Portland State University

PDXScholar

\title{
The Influence of Sense of Community on the Relationship Between Community Participation and Recovery for Individuals with Serious Mental Illnesses
}

Rachel Elizabeth Terry

Portland State University

Follow this and additional works at: https://pdxscholar.library.pdx.edu/open_access_etds

Part of the Mental and Social Health Commons

Let us know how access to this document benefits you.

\section{Recommended Citation}

Terry, Rachel Elizabeth, "The Influence of Sense of Community on the Relationship Between Community Participation and Recovery for Individuals with Serious Mental Illnesses" (2017). Dissertations and Theses. Paper 3679.

https://doi.org/10.15760/etd.5563

This Thesis is brought to you for free and open access. It has been accepted for inclusion in Dissertations and Theses by an authorized administrator of PDXScholar. Please contact us if we can make this document more accessible: pdxscholar@pdx.edu. 
The Influence of Sense of Community on the Relationship Between Community Participation and Recovery for Individuals with Serious Mental Illnesses

by

Rachel Elizabeth Terry

A thesis defense submitted in partial fulfillment of the requirements for the degree of

Master of Science

in

Psychology

Thesis committee:

Greg Townley, Chair

Joel Steele

Eric Mankowski

Portland State University

2017 


\begin{abstract}
The Community Mental Health Act of 1963 launched the deinstitutionalization movement, whereby individuals with serious mental illnesses were released from psychiatric hospitals and began living and receiving mental health care in the community (Carling, 1995). However, these actions have not necessarily integrated those individuals into all aspects of community life (Dewees, Pulice, \& McCormick, 1996). This is unfortunate because people with serious mental illnesses frequently report that community integration is not only important to them, but that it also aids in reducing symptoms and promoting recovery (Townley, 2015). Although past research suggests that receiving mental health care in the community has a positive impact on symptom management, the influence of other community factors (e.g., sense of community, community participation) has yet to be fully explored (Segal, Silverman, \& Temkin, 2010). Furthermore, there is lack of understanding as to how these community factors influence other aspects of recovery, such as mental and physical health. As such, the goal of the current study is to better understand the association between community participation and recovery by investigating sense of community as a potential mediating factor between community participation, psychological distress, mental health, and physical health. Data were collected from 300 adults with serious mental illnesses utilizing community mental health services in the United States. Results indicated that sense of community partially mediated the association between community participation and mental health, as well as psychological distress, and fully mediated the association between community participation and physical health. Implications include contributing
\end{abstract}


to the current knowledge base about the role of community factors in recovery and informing future interventions aimed at promoting community integration of adults with serious mental illnesses. 


\section{Acknowledgements}

I would like to thank my advisor, Dr. Greg Townley, for his unwavering support and guidance throughout this process. I would also like to thank my committee members, Dr. Joel Steele and Dr. Eric Mankowski, for their engagement in this project and advice along the way. Additionally, I would like to acknowledge the Temple University Collaborative on Community Inclusion and the contributions made by community mental health services across the country that made this research possible. Finally, I would like to thank my family and friends for all of their love and support, and my cohort for constantly providing encouragement and inspiration everyday.

The contents of this thesis were developed with the assistance of a grant from the National Institute on Disability, Independent Living, and Rehabilitation Research (NIDILRR; Grant \# 90RT5021-02-00; Mark Salzer, PI). However, the contents do not necessarily represent the policy of the U.S. Department of Health and Human Services, and endorsement by the Federal government should not be assumed. 
Table of Contents

Title

Page

Abstract. i

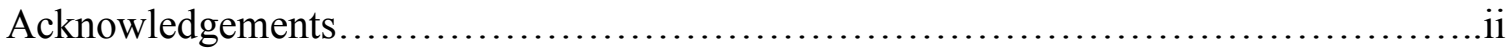

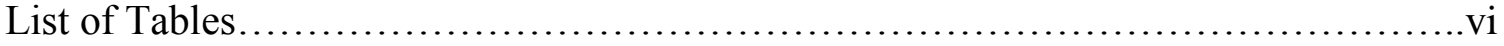

List of Figures.................................................................

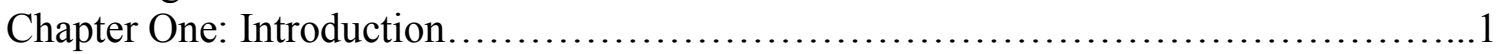

The Present Study .......................................................

Community Integration................................................... 3

Community Participation................................................... 5

Sense of Community.................................................... 8

The Relationship Between Community Participation and Sense of Community...9

Recovery........................................................ 10

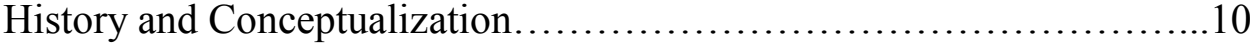

Psychological Distress..............................................13

Physical and Mental Health.........................................13

Chapter Two: Study Purpose, Research Questions, and Hypotheses....................17

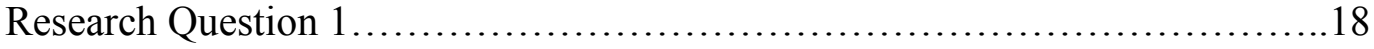

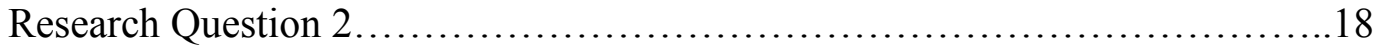

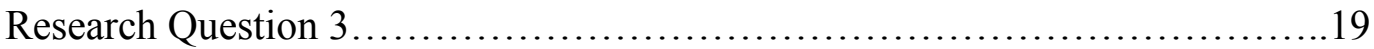

Research Question 4.................................................. 19

Chapter Three: Methods.................................................... 21

Participants.......................................................... 21

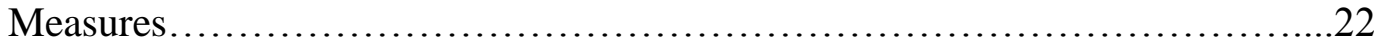

Community Participation........................................22

Sense of Community.........................................24

Psychological Distress...........................................25

Physical and Mental Health........................................26

Design and Procedues................................................. 26

Chapter Four: Data Analysis and Results...........................................28

Preliminary Analyses.................................................28

Differences Between Organizations and States......................28

Correlational Analyses...............................................29

Covariate Analyses.............................................. 30

Mediation Analyses.................................................... 32

Psychological Distress...........................................33

Mental Health................................................... 33

Physical Health.................................................. 34

Post-Hoc Analyses................................................... 35

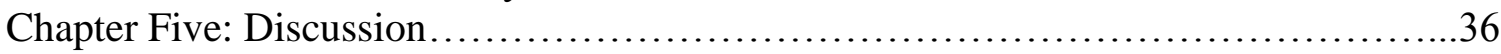

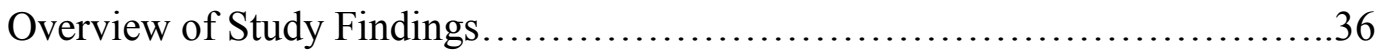

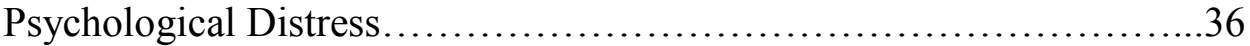

Mental Health and Physical Health................................... 37

Total Number of Participation Days.................................39 
Limitations and Future Research Directions......................................40

Implications for Research and Practice....................................44

Conclusion..........................................................48

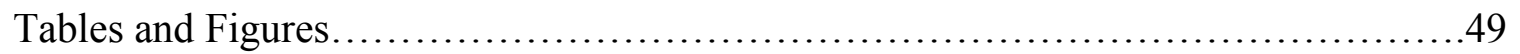

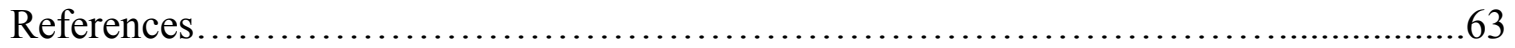

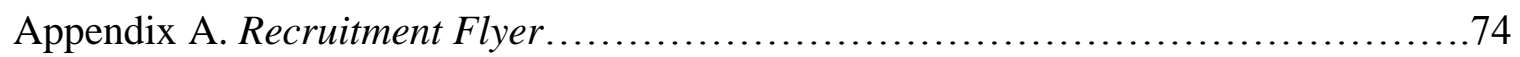

Appendix B. Measures..................................................... 75 
List of Tables

Table 1. Descriptive Statistics.............................................49

Table 2. Intraclass Correlation Coefficients for Primary Study Variables at Mental Health

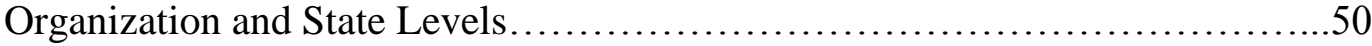

Table 3. Correlation Matrix of Study Variables....................................51

Table 4. Independent Samples T-Test: Outcome Variables by Gender...................52

Table 5. Independent Samples T-Test: Outcome Variables by Diagnosis..............53

Table 6. Summary of Mediation Model 1, with Psychiatric Distress as the Outcome.....54

Table 7. Summary of Mediation Model 2, with Mental Health as the Outcome...........55

Table 8. Summary of Mediation Model 3, with Physical Health as the Outcome........56 


\section{List of Figures}

Figure 1 .Conceptual Model of the Propose Mediation Analyses.....................57

Figure 2. Location of Partnering Community Mental Health Organizations with

Participant Recruitment Totals............................................58

Figure 3. Participant Recruitment Flow Chart.....................................59

Figure 4. Statistical Model of the Mediation Analyses with Psychological Distress as an

Outcome ...........................................................60

Figure 5. Statistical Model of the Mediation Analyses with Mental Health as an

Outcome.............................................................61

Figure 6. Statistical Model of the Mediation Analyses with Physical Health as an

Outcome........................................................62 
THE INFLUENCE OF SENSE OF COMMUNITY

\section{Chapter One}

\section{Introduction}

Until the mid- $20^{\text {th }}$ century, mental health care in the United States was primarily focused on psychiatric hospitalization, oftentimes admitting people with serious mental illnesses indefinitely, and usually in isolation (Carling, 1995). In 1963, the Community Mental Health Act instigated a shift in the focus of mental health care policies and prioritized moving people with serious mental illnesses out of psychiatric hospitals and into the community. However, subsequent policies did not support this act, and community mental health services were left with a disproportionate number of people living in the community without the proper resources to function independently (Carling, 1995).

To address this issue, the field of community mental health care has shifted towards promoting community integration, which is the belief that people with psychiatric disabilities should have the same opportunities as individuals without disabilities to live, form relationships, and experience a sense of belonging in their communities (Townley \& Kloos, 2011; Townley, Miller, \& Kloos, 2013; Wong \& Solomon, 2002). Individuals with serious mental illnesses have been diagnosed with at least one persistent psychiatric condition that significantly influences their life (Kloos, 2010). Previous research demonstrates that placing mental health services in the community is beneficial for people with serious mental illnesses, but there remains a lack of understanding about how other community factors work together to influence recovery (Nelson, Lord, \& Ochocka, 2001; Segal, Silverman, \& Temkin, 2010). For example, 
THE INFLUENCE OF SENSE OF COMMUNITY

encouraging participation in the community is critical because people with serious mental illnesses typically report feelings of social isolation and low community engagement (Townley, Kloos, \& Wright, 2009). Additionally, an absence of a sense of community may lead to psychological distress, expressed as increased psychiatric symptom severity (Townley \& Kloos, 2009). As such, community participation and sense of community may be important predictors of recovery among people with serious mental illnesses.

The World Health Organization states that mental illnesses are one of the leading causes of disability worldwide, with estimates that one in four people will experience a diagnosable mental illness at some point in their lives (WHO, 2001). Individuals with serious mental illnesses who are working towards recovery are not only seeking to reduce distressing symptoms, but also to gain improved health and well-being (Badger, McNiece, Bonham, Jacobson, \& Gelenberg, 2003). This is especially relevant because people with serious mental illnesses tend to experience worse physical and mental health than the general population (Jones et al., 2004; Robson \& Gray, 2006). Furthermore, the majority of research related to recovery for people with serious mental illnesses focuses on reducing symptoms and rarely examines other health-promoting factors. Therefore, it is important to explore a variety of interrelated factors such as psychological distress, mental health, and physical health when researching recovery for people with serious mental illnesses.

\section{The Present Study}

Now that the majority of people with serious mental illnesses are living in the community, research has moved towards understanding and optimizing community 
THE INFLUENCE OF SENSE OF COMMUNITY

integration (Townley \& Kloos, 2009). Although past research suggests that receiving mental health care in community settings has a positive impact on recovery, the influence of other community factors, such as community participation and sense of community, has yet to be fully explored (Segal, Silverman, \& Temkin, 2010). These factors may play an important role in integrating people with serious mental illnesses fully into their communities (Townley \& Kloos, 2009; Yanos, Felton, Tsemberis, \& Frye, 2007). There is also a lack of understanding about how these community factors influence other aspects of recovery such as mental and physical health. As such, the goal of the current study is to better understand the association between community participation and recovery by investigating sense of community as a potential mediating factor between community participation and recovery. In the following sections, key theories, constructs, and previous research surrounding these topics will be discussed to inform the current study and its specific research questions and hypotheses.

\section{Community Integration}

Although the deinstitutionalization movement successfully moved people with serious mental illnesses out of psychiatric hospitals and into the community, these actions have not successfully integrated those individuals into all aspects of community life or created inclusive communities (Dewees, Pulice, \& McCormick, 1996; Pinfold, 2002). Rather, mental health policies have typically placed people into community settings and left them without the proper supports to achieve independence in housing, activities, and relationships. This is unfortunate because people with serious mental illnesses frequently 
THE INFLUENCE OF SENSE OF COMMUNITY

report that community integration is not only important to them, but that it also aids in reducing symptoms and promoting recovery (Badger et al., 2003; Townley, 2015).

Previously, community integration was defined as the belief that people with disabilities should have the same opportunities to live and interact in the community as community members without disabilities (Wong \& Solomon, 2002). The majority of research focused on physical integration, defined as participants' use of community resources and involvement in community activities beyond community mental health centers (Wong \& Solomon, 2002). However, Wong and Solomon (2002) noted that community integration encompasses far more than merely being physically integrated into the community and suggested that the construct should be expanded to include social integration and psychological integration. Social integration encompasses a person's social network and the social relationships developed within this network, as well as regular interactions with community members (e.g., neighbors, coworkers, and members of religious or spiritual organizations). Psychological integration refers to a person's perceived sense of belonging, community membership, emotional connections with community members, and ability to influence the community. Wong and Solomon (2002) argued that all three components are necessary for a person to be successfully integrated into the community and suggested that future research should examine the influence of social and psychological integration when considering community integration for people with serious mental illnesses.

Despite increased awareness of the importance of community integration, people with serious mental illnesses typically report feelings of social isolation and low levels of 
THE INFLUENCE OF SENSE OF COMMUNITY

community engagement (Badger et al., 2003; Dewees, Pulice, \& McCormick, 1996;

Pinfold, 2002; Townley, Kloos, \& Wright, 2009). For example, Pinfold (2002) observed that while community integration has become central to mental health policy, people with mental health problems continue to experience social isolation. After completing qualitative interviews and observations with mental health staff and service users, Pinfold (2002) argued that participation in both mainstream and segregated activities is an important factor in community integration. Additionally, Dewees, Pulice, \& McCormick (1996) investigated the effects of a policy in Vermont that aimed to move people with serious mental illnesses out of psychiatric hospitals and into the community. Results indicated that people had trouble obtaining adequate health care services, regularly experienced mental health stigma, had small social networks that mostly stemmed from mental health services, and did not often utilize community resources (Dewees, Pulice, \& McCormick, 1996). The results of these studies suggest that although mental health policies strive towards promoting community integration, implementation of these policies has not been entirely successful, and additional research regarding factors that promote full community inclusion is needed.

\section{Community Participation}

The President's New Commission on Mental Health (2003) highlights the importance of community participation for people with serious mental illnesses by stating that recovery refers to "the process in which people are able to work, learn, and participate fully in their communities" (pg. 5). Community participation for people with serious mental illnesses is defined as independent engagement in community-based 
THE INFLUENCE OF SENSE OF COMMUNITY

contexts across any of the following social life domains: domestic life (e.g., cleaning, shopping), interpersonal life (e.g., formal relationships, intimate relationships, family relationships), major life activities (e.g., education and employment), and community, civic, and social life (e.g., politics, religion, culture) (WHO, 2001). There has been limited research on aspects of community participation for people with serious mental illnesses beyond domestic life (Salzer, Brusilovskiy, Prvu-Bettger, \& Kottsieper, 2014). Past research indicates that areas such as using public transportation, running errands, going to restaurants, and shopping tend to have the highest reported levels of participation and are also among the most important activities reported by individuals with serious mental illness (Salzer et al., 2014). However, research suggests that members of this population do not participate in activities that are important to them as much as they would prefer (Salzer et al., 2014). Furthermore, it is unclear whether the frequency or the variety of participation in these activities positively influences recovery for people with serious mental illnesses. Therefore, it is important to research these components of community participation because forming relationships, performing valued social roles (e.g., employment, volunteer work, and education), and engaging with the community may combat the negative effects of psychological symptoms and social isolation.

Past research suggests that community participation has several benefits for people with serious mental illnesses, including a better quality of life and recovery (Badger et al., 2003; Kaplan, Salzer, \& Brusilovsky, 2012), as well as greater overall life satisfaction (Prince \& Gerber, 2005). For example, Badger et al. (2003) employed a case 
THE INFLUENCE OF SENSE OF COMMUNITY

study research design to interview people with serious mental illnesses who use public mental health services. Participants reported that community activities were important to recovery, but they did not participate as actively as they would prefer due to a lack of opportunities (Badger et al., 2003). Additionally, while investigating community participation for people with serious mental illnesses, Wieland et al. (2007) reported that participants who established casual relationships with a larger number of community members, such as store employees and wait staff, had stronger perceptions of belonging and overall life satisfaction. Research has also demonstrated that these casual community relationships (also called distal supports) significantly predict community integration and recovery even after controlling for traditional social support systems (e.g., friends and family; Townley, Miller, \& Kloos, 2013). Furthermore, people with larger activity spaces (i.e., those who participate in more activities across larger distances in their communities) reported higher life satisfaction compared to people with smaller activity spaces (Townley, Kloos, \& Wright, 2009). Finally, Kaplan, Salzer, \& Brusilovsky (2012) investigated the impact of community participation on recovery and quality of life for adults with serious mental illnesses. Results of their study indicated that components of participation such as civic engagement, friendship, group membership, and employment were positively associated with greater recovery and quality of life. The research outlined above suggests that community participation is associated with positive benefits; however, it is likely that an increased sense of community, developed through relationships and social ties in the community, may have the strongest influence on positive outcomes such as recovery. This will be discussed in more detail below. 
THE INFLUENCE OF SENSE OF COMMUNITY

\section{Sense of Community}

When people spend more time actively participating in their communities, they are likely to develop a sense of belonging, or connectedness, to the community. A sense of community may be a key component to promoting community integration beyond the role of participation in community activities (Cummins \& Lau, 2003). Additionally, while physical integration and participation are important aspects of community integration, social and psychological integration may be necessary to increase recovery. As such, research and practice should place additional emphasis on fostering social opportunities rather than only opportunities for physical integration (Cummins \& Lau, 2003).

Sarason (1974) first conceptualized the idea of a psychological sense of community, defining it as the feeling that one belongs to, and participates in, a larger collective of individuals. He asserted that a sense of community is important to overall health and well-being, particularly for individuals who have been marginalized or segregated from community life (Sarason, 1974). McMillan and Chavis (1986) later proposed a theoretical framework for sense of community that included the following four components: membership, influence, integration and fulfillment of needs, and shared emotional connection. First, membership is characterized by feelings of belonging, emotional security, and identification. Second, influence is the ability for members to influence a group, and vice versa, for a cohesive group to be able to influence members. Third, integration and fulfillment of needs implies that the group is capable of satisfying the physical and psychological needs of its members, which will reinforce members' 
THE INFLUENCE OF SENSE OF COMMUNITY

commitment to the group. Finally, shared emotional connection stems from sharing or identifying with the history of a community through personal investment and interaction with other members of the community.

Past research suggests that people with serious mental illnesses experience health benefits from factors such as sense of community and relationships with community members in a similar manner as the general population (Kloos \& Townley, 2011; Yanos, Stefanic, \& Tsemberis, 2011). Additionally, an absence of a sense of community may have a variety of negative consequences, such as feelings of alienation, loneliness, and psychological distress (McMillan \& Chavis, 1986; Sarason, 1974). For people who experience serious mental illnesses, this can be expressed specifically through an increase in the number or severity of psychiatric symptoms (Townley \& Kloos, 2009). Previous research has also shown that sense of community may play an important role in recovery for people with serious mental illnesses. Specifically, the more that individuals with serious mental illnesses feel that they belong in their neighborhoods, the less psychiatric distress they report (Kloos \& Townley, 2011). Finally, in a study conducted by Gulcur, Tsemberis, Stefancic, and Greenwood (2007), participants who experienced more psychological symptoms reported lower psychological integration (i.e., perceptions of belonging). Thus, a strong sense of community may be an important catalyst for recovery among people with serious mental illnesses.

\section{The Relationship Between Community Participation and Sense of Community}

Talò, Mannarini, \& Rochira (2014) completed a meta-analytic review to investigate the relationship between sense of community and community participation. 
THE INFLUENCE OF SENSE OF COMMUNITY

After reviewing the empirical research literature, they noted a significant positive correlation between community participation and sense of community. Furthermore, they reviewed theoretical discussions of the two constructs and found that most researchers argue that sense of community and community participation have a circular relationship, such that community participation reinforces sense of community while sense of community boosts community participation. On the one hand, if people actively participate in the community, they may develop a sense of belonging to the community. On the other hand, if people already have a strong sense of community they may be more likely to venture out and participate in community activities. Previous empirical research suggests that community participation is likely to lead to an increase in sense of community (Chavis, Hogge, McMillan, \& Wandersman, 1986; Prince \& Gerber, 2005). For example, Prince and Gerber (2005) found that while sense of community and community participation were both significantly related to overall life satisfaction in a sample of individuals with serious mental illnesses, they suggested that community participation is likely to lead to enhanced sense of community. Given the importance of sense of community and community participation, it is important to consider how these constructs work together to impact recovery for people with serious mental illnesses.

\section{Recovery}

History and conceptualization. Mental health policies have shifted to focusing on community integration both because of its social benefits and also because research suggests that it promotes recovery for people with serious mental illnesses (Abdallah et al., 2009; Kloos \& Townley, 2011; Prince \& Gerber, 2005; Whitley \& Drake, 2010). The 
THE INFLUENCE OF SENSE OF COMMUNITY

formerly accepted understanding within the mental health field was that adults with serious mental illnesses could not recover and that mental health services should focus on symptom maintenance rather than increasing quality of life and general health (Anthony, 2000). However, the emergence of consumer narratives about recovery and the resulting increase in empirical research related to recovery altered this understanding for the better. People with serious mental illnesses began sharing detailed accounts of personal growth and development that focused on moving beyond the damaging effects of mental illness and learning to live a meaningful life in the community (Anthony, 1993). At the same time, Harding (1994, as cited in Anthony, 2000) reviewed numerous longitudinal studies and found that most people with serious mental illnesses did not suffer a deteriorating disease course after initial diagnosis. She found that, instead, recovery from mental illnesses was happening. Furthermore, Harding, Zubin, \& Strauss (1987) suggested that there are environmental and social factors that influence the continuing effects of mental illnesses beyond individual functioning, including reduced economic opportunities, negative effects of institutionalization, and lower social status resulting from pervasive mental health stigma.

The National Institute of Mental Health (NIMH) developed the community support system (CSS) model in light of the consumer narratives and empirical research related to recovery. The CSS model outlines ways that mental health services can provide assistance for adults with serious mental illnesses and focuses on their full inclusion in all aspects of the community (Anthony, 1993). Additionally, psychiatric rehabilitation studies recognized that the impact of severe mental illnesses on individuals includes 
THE INFLUENCE OF SENSE OF COMMUNITY

disability, disadvantage, and dysfunction, as well as impairment (i.e., symptoms). The combination of the CSS model and the rehabilitation model led to a focus on recovery in the 1990 s and into the $21^{\text {st }}$ century. Anthony (1993) used these two models to discuss how mental health services can become recovery-oriented. He and his colleagues suggested that recovery outcomes include symptom reduction, increased sense of wellbeing, increased physical and spiritual health, and becoming an active member of the community (Farkas, Gagne, Anthony, \& Chamberlin, 2005).

In more recent theoretical work related to recovery, Whitley \& Drake (2010) proposed five dimensions of recovery for people with serious mental illnesses: clinical, existential, functional, physical and social. Clinical recovery is considered to be the reduction and control of symptoms, such that symptoms do not disable the individual. Existential recovery aims to enhance personal feelings of control, hope, and empowerment. Functional recovery is defined as the ability to participate in aspects of daily life that facilitate community integration (e.g., employment, housing, education). Physical recovery refers to improvements in physical health and well-being. Finally, social recovery focuses on improving relationships with others and integrating into the community.

Whitley \& Drake (2010) suggest that the five dimensions of recovery presented in their theoretical framework overlap in the lives of people with serious mental illnesses and argue that an increase in any of the dimensions is likely to positively affect other dimensions, as well as recovery as a whole. Therefore, it logically follows that the combination of both community participation (which is an aspect of functional recovery) 
THE INFLUENCE OF SENSE OF COMMUNITY

and sense of community (an aspect of social recovery) may work together to improve clinical and physical recovery. For the purpose of the current study, recovery will be operationalized as lower psychological distress, higher mental health, and higher physical health; and these variables will be considered outcomes of community participation and sense of community.

Psychological distress. Although conceptualizations of recovery have moved beyond solely focusing on clinical recovery, people with serious mental illnesses continue to identify medication and symptom management as critical components of the recovery process (Corrigan, Salzer, Ralph, Sangster, \& Keck, 2004; Smith, 2000). Past research suggests that community integration leads to a reduction of symptoms, a decrease in symptom severity, and less overall psychiatric distress (Abdallah et al., 2009; Badger et al., 2003; Kloos \& Townley, 2011; Prince \& Gerber, 2005). For example, Prince and Gerber (2005) found that community integration was associated with symptom severity, such that people who reported higher levels of community integration also reported less severe symptom distress than people with lower levels of community integration. A review of literature about other social factors that influence recovery suggests that empowerment, developing positive social identities, fostering supportive personal relationships, and social inclusion may promote recovery (Tew, Ramon, Slade, Bird, Melton \& Le Boutillier, 2011). For instance, a larger social network and subjective ratings of its supportiveness have been noted as predictors of recovery (Corrigan \& Phelan, 2004; Hendryx et al., 2009; Mattsson et al., 2008).

Physical and mental health. Although symptom management plays a critical 
THE INFLUENCE OF SENSE OF COMMUNITY

role in recovery for people with serious mental illnesses, it is important to recognize that recovery encompasses more than just a lack of symptoms; it also includes an overall sense of well-being characterized by positive physical and mental health (Salyers, Bosworth, Swanson, Lamb-Pagone, \& Osher, 2000). People with serious mental illnesses have reported that management of mental health challenges requires a focus on improving general health and social functioning in addition to symptom management (Badger et al., 2003). While community participation has been found to be associated with improvements in general mental health (Tsai \& Rosenheck, 2012), the vast majority of research examining the influence of community experiences on recovery for people with serious mental illnesses has not included physical and mental health as outcome variables.

Research suggests that individuals with serious mental illnesses are not as physically healthy as the general population and are more likely to experience physical illnesses such as diabetes, obesity, and cardiovascular and respiratory diseases (Jones et al., 2004; Robson \& Gray, 2006). For example, in a study of Medicaid claims of people with serious mental illnesses, $75 \%$ had a single chronic health condition and $50 \%$ experienced two or more chronic health conditions (Jones et al., 2004). Furthermore, mortality rates for people with serious mental illnesses tend to be an average of 25 years earlier than the general population (Parks, Svendsen, Singer, \& Foti, 2006). Colton and Manderscheid (2006) conducted a study comparing the mortality rates of public mental health clients to the general population in six states. Overall, public mental health clients had a higher relative risk of death, with the actual number of deaths ranging from 1.2 to 
THE INFLUENCE OF SENSE OF COMMUNITY

4.9 times higher than the expected number of deaths in each state. Additionally, clients diagnosed with a major mental illness (e.g., schizophrenia, bipolar disorder, major depressive disorder) died up to ten years earlier on average than clients with non-major mental illnesses (e.g., anxiety disorders and dysthymia). Public mental health clients were also more likely to die from automobile accidents and suicide than the general population (Colton \& Manderscheid, 2006).

There are several factors that contribute to the poorer physical health of people with serious mental illnesses, including reduced social networks, mental health stigma, lower socioeconomic status, inadequate access to health care, and lack of opportunities that positively impact physical health and healthy behaviors (Lawrence \& Kisely, 2010; Robson \& Gray, 2006). Factors that may exacerbate physical health problems among individuals with serious mental illnesses include social isolation and a lack of community participation. Social isolation is known to lead to increased mortality, physiological aging, cognitive decline, and an increase in negative feelings such as depression, anxiety, and stress (Hawkley \& Cacioppo, 2010).

Seeman (1996) conducted a review of epidemiological research to examine the relationship between social integration and a variety of health factors. Findings from studies examining social integration and physical health were mixed, revealing positive effects, negative effects, and non-significant effects of social integration on disease incidence, disease severity, and recovery from stroke. These results, however, may not be generalizable to general assessments of physical health (e.g., health as a barrier to completing daily activities; perceptions of pain) because the author focused only on 
THE INFLUENCE OF SENSE OF COMMUNITY

specific physical health outcomes (e.g., stroke, disease severity). Similarly, research

investigating the influence of social integration on mental health tends to have

inconclusive or conflicting results. The research that has been more conclusive suggests

that, social integration may play a protective role for mental health by reducing feelings

of social isolation (Seeman 1996). In an attempt to explain these results, Berkman, Glass,

Brissette, and Seeman (2000) developed a conceptual framework utilizing social

networks and its many components, including social integration as a mediating factor.

The authors argue that social integration is a psychosocial pathway that utilizes a

person's social network to influence his or her health. In other words, social integration

facilitates a sense of belonging and attachment to the community, and it is this resulting

sense of community that affects health outcomes (Berkman et al., 2000).

The majority of research solely examines what factors predict symptoms distress and symptom reduction for people with serious mental illnesses. There is a lack of research investigating the relationship between community factors and other aspects of recovery (Berkman et al., 2000; Seeman, 1996). Accordingly, the current study aims to provide a first step in analyzing the influence of community participation and sense of community on physical and mental health. Inclusion of physical and mental health as outcome variables also supports the recovery-oriented approach for community mental health services outlined by William Anthony (1993). 


\section{THE INFLUENCE OF SENSE OF COMMUNITY}

\section{Chapter Two}

\section{Study Purpose, Research Questions, and Hypotheses}

The proposed study aims to contribute to the current knowledge base regarding the influence of community factors on recovery for individuals with serious mental illnesses. It also aims to inform future interventions focused on increasing community integration and recovery among members of this population. The goal of the current study is to investigate sense of community as a potential mediating factor between community participation, psychological distress, mental health, and physical health (see Figure 1, and in Appendix I). It is hypothesized that people with serious mental illnesses who participate more frequently in community activities will report less psychological distress, and better mental and physical health, than people who participate less frequently. Additionally, it is expected that individuals with serious mental illnesses who participate more frequently in community activities will report a stronger sense of community compared to those who do not participate as frequently. Further, it is expected that people with serious mental illnesses who report a stronger sense of community will also report less psychological distress and better mental and physical health than individuals who report lower levels of sense of community. Finally, it is hypothesized that sense of community will be the primary mechanism responsible for the relationship between community participation, psychological distress, mental health, and physical health. That is, sense of community will mediate the relationship between community participation and each of these three outcomes. 
THE INFLUENCE OF SENSE OF COMMUNITY

In sum, the current study addresses the following research questions and related hypotheses.

Research Question 1: What is the role of community participation in predicting the following recovery variables for people with serious mental illnesses?

a. Psychological distress

b. Mental health

c. Physical health

Hypothesis 1a: Community participation will be negatively and significantly related to psychological distress, such that higher community participation will be associated with lower psychological distress.

Hypothesis 1b: Community participation will be positively and significantly related to mental health, such that higher community participation will be associated with greater mental health.

Hypothesis 1c: Community participation will be positively and significantly related to physical health, such that higher community participation will be associated with greater physical health.

Research Question 2: What is the role of community participation in predicting sense of community for people with serious mental illnesses?

Hypothesis 2: Sense of community will be positively and significantly related to community participation, such that higher community participation will be associated with higher sense of community. 
THE INFLUENCE OF SENSE OF COMMUNITY

Research Question 3: What is the role of sense of community in predicting the following recovery variables for people with serious mental illnesses?
a. Psychological distress
b. Mental health
c. Physical health

Hypothesis 3a: Sense of community will be negatively and significantly related to psychological distress, such that higher sense of community will be associated with lower psychological distress.

Hypothesis 3b: Sense of community will be positively and significantly related to mental health, such that higher sense of community will be associated with greater mental health.

Hypothesis 3c: Sense of community will be positively and significantly related to physical health, such that higher sense of community will be associated with greater physical health.

Research Question 4: Does sense of community mediate the association between community participation and the following variables?

a. Psychological distress

b. Mental health

c. Physical health

Hypothesis 4a: The association between community participation and psychological distress will be mediated by sense of community, such that lower 
THE INFLUENCE OF SENSE OF COMMUNITY

psychological distress will be largely explained by higher levels of sense of community rather than higher levels of community participation alone.

Hypothesis 4b: The association between community participation and mental health will be mediated by sense of community, such that greater mental health will be largely explained by higher levels of sense of community rather than higher levels of community participation alone.

Hypothesis 4c: The association between community participation and physical health will be mediated by sense of community, such that greater physical health will be largely explained by higher levels of sense of community rather than higher levels of community participation alone.

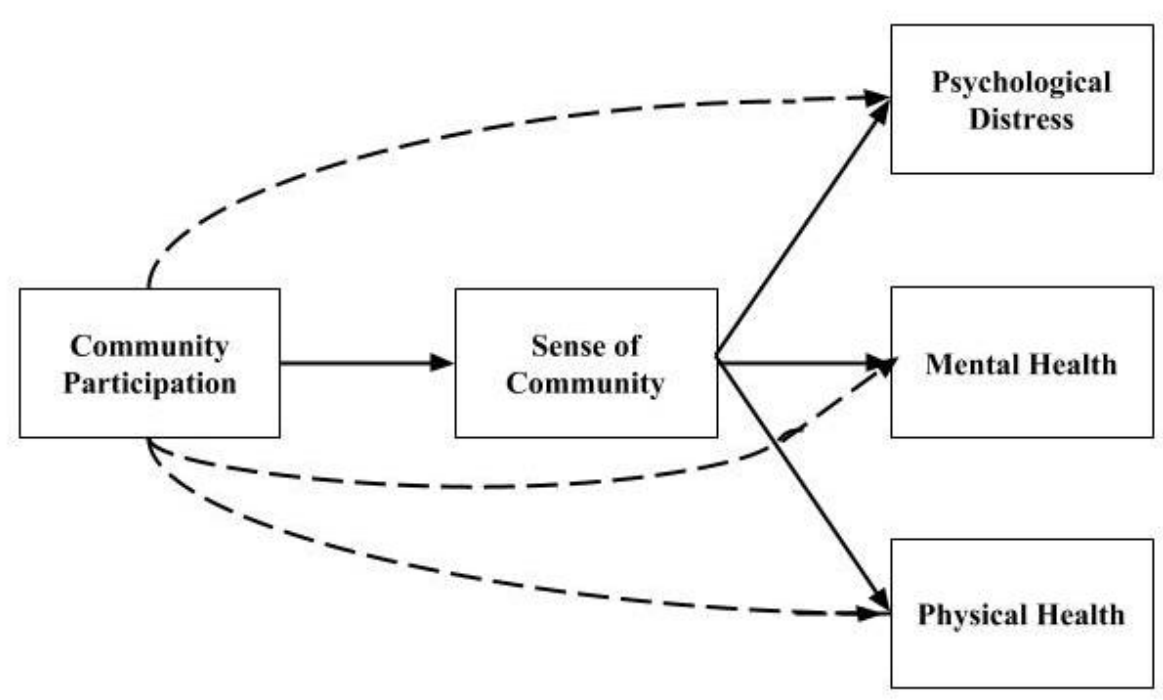

Figure 1. Conceptual model of the proposed mediation analyses. 


\section{THE INFLUENCE OF SENSE OF COMMUNITY}

\section{Chapter Three}

\section{Participants}

\section{Method}

The proposed study utilized data collected from 300 adults with serious mental illnesses using community mental health services in the United States who were recruited to take part in a larger study examining community participation. Individuals were recruited from 21 mental health service organizations in 15 different states (see Figure 2). The organizations were contacted through email campaigns and announcements, as well as personal communication. The majority of the organizations were outpatient treatment programs, but organizations also included community support programs, peer support programs, and residential treatment programs. Participants were recruited via flyers posted in common areas of the mental health organizations and distributed by case managers and other staff members. The flyer stated that researchers were interested in understanding factors related to community participation and informed potential participants that they were recruiting people with psychiatric disabilities who use publicly-funded mental health services (see Appendix II). The flyer stated that the information would be used to influence policies and interventions. Eligible individuals would complete a one-hour survey over the phone and would receive $\$ 20$ as compensation. A flow chart presents the recruitment process and reflects the number of individuals who expressed interest and those who were deemed ineligible for various reasons (see Figure 3).

Inclusion criteria for this study were as follows: adults between the ages of 18-65; self-reported diagnosis of either schizophrenia-spectrum disorder or major affective 
THE INFLUENCE OF SENSE OF COMMUNITY

disorder (e.g., major depression and bipolar); self-reported limitations related to mental

illness that occurred in the last 12 months; eligibility for Medicaid or state-equivalent benefit program; and willingness to provide a residential address. Exclusion criteria applied to individuals who were unable to provide informed consent or had a legal guardian.

Demographics. The average participant age was $46(\mathrm{SD}=11.23)$, and $60 \%$ were female. The majority of the participants were White (65\%; Black, $28 \%$; Other, $7 \%)$. The majority of participants reported a diagnosed mood disorder (230, 77\%), while 129 (43\%) reported a schizophrenia-spectrum disorder. Diagnostic percentages total more than $100 \%$ because participants were asked to report any current diagnoses, and some reported more than one diagnosis. Other sample demographics relevant to the current study include relationship status (64\% single), employment (16\% currently working for pay), and housing situation (57\% reported living in their own apartment, home, or condo). Finally, a total of 72 participants (24\%) reported having been hospitalized for a mental health or psychiatric issue in the six months prior to being interviewed.

\section{Measures}

Community participation. To measure community participation, a modified 22item version of the Temple University Community Participation Measure (TUCP; Salzer, Brusilovskiy, Prvu-Bettger, \& Kottsieper 2014) was used (see Appendix III). Participants were asked about 22 different activities (e.g., going to the library, shopping, visiting with friends or family) in which they participated in the last 30 days without assistance from mental health staff. For this measure, two participation constructs were computed: the 
THE INFLUENCE OF SENSE OF COMMUNITY

total number of different areas performed at least once in the past 30 days, with possible scores ranging from 0 to 22; and the total number of days of participation in the past 30 days across the 22 areas, with possible scores ranging from 0 to 660 (30 days x 22 participation areas). The internal reliability (i.e., Cronbach's alpha) for the construct measuring number of participation areas in this sample was .71. The internal reliability for the construct measuring number of participation days in this sample was .68. For the purposes of this study, I measured community participation as the number of different areas in which activity occurred, with possible scores ranging from 0 to 22 .

A previous study by Salzer, Kottsieper, and Brusilovskiy (2015) demonstrated intermethod reliability by comparing the measure to a similar diary checklist. Results showed significant Spearman correlations for participation areas ranging from 0.20 to 0.89. Furthermore, the total number of participation days and the total number of different participation areas were significantly correlated $(0.76$ and 0.65 , respectively; Salzer, Kottsieper, \& Brusilovskiy, 2015). In addition, Salzer, Brusilovskiy, PrvuBettger, \& Kottsieper (2014) assessed test-retest reliability by comparing the measure at two time points within 24 to 72 hours. The analyses found significant Pearson correlations for days of participation in each area at Time 1 and 2 ranging from 0.27 to 0.85). Furthermore, the categorical responses had a statistically significant level of agreement (50\%) when compared to chance using a binomial test. Finally, at least $50 \%$ of participants responded that 22 of the 26 areas were important to them (Salzer, Brusilovskiy, Prvu-Bettger, \& Kottsieper, 2014). 
THE INFLUENCE OF SENSE OF COMMUNITY

To provide evidence for validity, a Pearson correlation was conducted to examine the association between total number of activities and World Health Disability Assessment Schedule (WHO-DAS 2.0; Üstün, et al., 2010). The WHO-DAS measures the levels of impairment that an individual experienced in the past 30 days. An example of an item on this scale is "In the past 30 days, how much difficulty did you have in taking care of household responsibilities" (Üstün et al., 2010). Consequently, individuals who report higher levels of community participation should also report lower levels of impairment. The results indicated that that community participation was significantly negatively correlated with the WHO-DAS health and disability score $r(298)=-.18, p<$ .01 .

Sense of community. In order to assess participants' sense of community, 13 items from the Sense of Community Index-2 (SCI-2; Chavis, Lee, \& Acosta, 2008) were used. Participants were instructed to think about their broader community and respond to each item in terms of how they generally feel about their community. The Sense of Community Index-2 consists of 24 statements that assess dimensions of membership, influence, fulfillment of needs, and shared emotional connection (e.g., "Community members and I value the same things"). A subset of the full measure was chosen due to constraints in phone survey length; and items were selected based on their relevance for individuals with serious mental illnesses, as well as ensuring representation from all four subscales (G. Townley, personal communication, April 21, 2016). Participants responded to each statement using a 4-point scale ranging from 1 (not at all) to 4 (completely). The 
THE INFLUENCE OF SENSE OF COMMUNITY

scale was analyzed as an average of the 13 items, with the internal reliability in this sample computed as .91.

To provide evidence for the validity of this modified sense of community measure, a Pearson correlation was conducted to examine the association between total number of activities and the Devaluation-Discrimination scale (Link, Cullen, Struening, Shrout, \& Dohrenwend, 1989). The Devaluation-Discrimination scale measures the levels of stigma that individuals perceive from community members about people with serious mental illnesses. An example of an item on the Devaluation-Discrimination scale is "Most people in my community would treat someone with a mental illness diagnosis just as they would treat anyone" (Link et al., 1989). Therefore, individuals who report higher levels of sense of community should also report lower levels of stigma, as has been reported in previous research (Townley \& Kloos, 2011). The results indicated that sense of community was significantly negatively correlated with stigma $r(292)=-.39, p<.001$.

Psychological distress. In order to assess the participants' psychological distress, a 25-item version of the Hopkins Symptoms Checklist (HSCL-25; Derogatis, Lipman, Rickels, Uhlenhuth, \& Covi, 1974) was used. Participants were read a list of psychological symptoms and complaints and were asked how much each symptom distressed them in the past week (e.g., "being scared for no reason”). Participants responded to each statement using a 4-point scale ranging from 1 (not at all) to 4 (extremely). The scale was analyzed as an average of 25 items, and the internal reliability in this sample was .94. The validity of the HSCL-25 has been well documented, and the 
THE INFLUENCE OF SENSE OF COMMUNITY

scale is commonly used to measure psychological distress in various populations (Veijola et al., 2003; Sandanger et al., 1998).

Physical and mental health. To measure participants' physical and mental health, a 12-item version of the Short-Form Health Survey (SF-12; Ware, Kosinski, \& Keller, 1996) was used. In this measure, participants were asked about their views on their own health in the past month (e.g., "How much did pain interfere with your normal work"). Participations responded to four of the statements using a 5-point scale ranging from 1 (all the time) to 5 (none of the time). The response set for another of the statements is a 5-point scale ranging from 1 (excellent) to 5 (poor), another at a 3-point scale ranging from 1 (yes, limited a lot) to 3 (no, not limited at all), and finally a statement with a 5-point scale ranging from 1 (not at all) to 5 (extremely). Scoring software provided by Optum ${ }^{\mathrm{TM}}$ (2016) was used to clean and score SF-12 data. This software addresses missing data and creates summary measures based on sample and population averages. The summary measures are divided into a physical health component score (PCS) based on the following scales: physical functioning, rolephysical, bodily pain, and general health; and a mental health component score (MCS) based on the following scales: vitality, social functioning, role-emotional, and mental health. The internal reliability for the PCS and MCS was .76 and .77, respectively. The validity of the SF-12 has been previously established, and the scale is frequently used to measure physical and mental health (Tunis, Croghan, Heilman, Johnstone, \& Obenchain, 1999; Ware, Kosinki, \& Keller, 1996).

\section{Design and Procedures}




\section{THE INFLUENCE OF SENSE OF COMMUNITY}

The current study used survey-based methods in a cross-sectional design. The research protocol included measures of community participation, civic engagement, access to community resources, perceptions of neighborhoods, sense of community, stigma, loneliness, psychological distress, and quality of life. Data were collected during a phone interview, and research assistants recorded participants' answers electronically into an online survey platform. Participants provided informed consent and agreed to participate in exchange for a $\$ 20$ incentive. Interviews lasted about one hour on average. The study was approved by the Institutional Review Boards of the sponsoring Universities (Portland State University and Temple University) in addition to review boards within the Departments of Mental Health when required by partnering agencies. 
THE INFLUENCE OF SENSE OF COMMUNITY

Chapter Four

\section{Data Analysis and Results}

\section{Preliminary Analyses}

Prior to conducting analyses, data were visually screened to detect outliers and errors in data entry using boxplots and scatterplots. Outliers were present in both total number of participation days and activities and there was a single outlier in the mental health component score. However, all outliers were retained because the values occurred within a plausible range for each of the variables. There was very little missing data in this study. None of the variables were missing more than three participant responses (i.e., no more than $1 \%$ missing data on any single variable).

Frequency distributions and summary statistics were examined to confirm that the data are normally distributed and fall within a plausible range of values for each variable (see Table 1). Tests of skewness and kurtosis revealed that community participation, measured by the number of participation days, was positively skewed and peaked. However, these values were within the range of acceptable values proposed by less conservative guidelines that state that absolute skewness values lower than three and absolute kurtosis values lower than 10 are sufficient (Kline, 2011). Therefore, the untransformed data were used for the analyses.

Differences between organizations and states. Because the data for this study were collected from individuals from different mental health organizations in different states, it was necessary to determine if scores differed significantly by mental health organization and by state. The intraclass correlation coefficient (ICC) was computed for 
THE INFLUENCE OF SENSE OF COMMUNITY

each of the primary study variables (i.e., sense of community, community participation, psychological distress, mental health, physical health) at both mental health organization and state levels (see Table 2). In general, ICCs above .10 indicate that a significant amount of variance is accounted for by the nesting variable (i.e., the organization or state); and thus, a multi-level modeling framework may be needed to address potential attenuation in standard errors and increased risk of rejecting the null hypothesis when it may indeed be true (i.e., a Type 1 error). Given the low values of the ICCs for primary variables in the current study (all are below .10, and most are below .05), it is acceptable to proceed with analyses using the general linear model rather than a multi-level design.

Correlational analyses. Correlational analyses between primary study variables were conducted, and a correlation matrix is presented in Table 3. First, total number of activities was significantly positively correlated with total number of activity days $(r=$ $.66)$, sense of community $(r=.25)$, and mental health $(r=.18)$; and significantly negatively correlated with psychological distress $(r=-.18)$. Second, total number of activity days was significantly positively correlated with total number of activities, sense of community $(r=.18)$, and mental health $(r=.14)$. Third, sense of community was significantly positively correlated with total number of activity days, total number of activities, physical health $(r=.17)$, and mental health $(r=.31)$; and significantly negatively correlated with psychological distress $(r=-.32)$. Fourth, psychological distress was significantly negatively correlated with total number of activities, sense of community, physical health $(r=-.35)$, and mental health $(r=-.61)$. Fifth, physical health was significantly positively correlated with sense of community and significantly 
THE INFLUENCE OF SENSE OF COMMUNITY

negatively correlated with psychological distress. Finally, mental health was significantly

positively correlated with total number of activity days, total number of activities, and sense of community; and significantly negatively correlated with psychological distress.

The regression analyses are likely to be influenced by the higher correlations between predictor variables; specifically, multicollinearity may render the effects undetectable. All of the variables were expected be correlated, as the variables aim to measure constructs that have been demonstrated to be related to each other. In fact, the correlations show strong support for the proposed hypotheses. As community participation increases, sense of community, mental health, and physical health increases while psychological distress decreases. Similarly, as sense of community increases, mental health and physical health increases while psychological distress decreases.

Covariate analysis. Consistent with past research, race, gender, age, and diagnosis were considered as potential covariates (Davis, Townley, \& Kloos, 2013). Participants' current living situation was also tested as a potential covariate because people who live in their own homes or apartments may have very different perceptions of community participation, sense of community, and recovery than participants living in more controlled settings or with family members. A new variable was computed that categorized participants into either living in their own homes (e.g., apartment, house) or not (e.g., group home).

A series of independent samples t-test indicated that there were no significant differences in the mediator or outcome variables by race or current living situation. However, there were significant differences by gender for sense of community, 
THE INFLUENCE OF SENSE OF COMMUNITY

psychological distress, physical health, and mental health (see Table 4). First, sense of community was significantly higher for males $(M=2.58, S D=.74)$ than females $(M=$ 2.33, $S D=.73), t(296)=-2.87, p<.05$. Second, psychological distress was significantly lower for males $(M=1.89, S D=.60)$ than females $(M=2.23, S D=.65), t(294)=4.50, p$ $<.05$. Third, physical health was significantly higher for males $(M=47.17, S D=9.41)$ than females $(M=42.73, S D=11.21), t(278.08)=-3.68, p<.05$. Fourth, mental health was significantly higher for males $(M=40.35, S D=10.29)$ than females $(M=37.85, S D$ $=10.65), t(295)=-2.01, p<.05$.

Furthermore, there were significant differences by diagnosis for sense of community, psychological distress, and mental health (see Table 5). Sense of community was significantly higher for participants diagnosed with a schizophrenia-spectrum disorder $(M=2.56, S D=.76)$ compared to individuals without a schizophrenia-spectrum diagnosis $(M=2.33, S D=.71), t(298)=-2.64, p<.05$. Psychological distress was significantly lower for participants diagnosed with a schizophrenia-spectrum disorder ( $M$ $=2.00, S D=.62$ ) compared to individuals without a schizophrenia-spectrum diagnosis $(M=2.16, S D=.67), t(296)=2.10, p<.05$. Mental health was significantly higher for participants diagnosed with a schizophrenia-spectrum disorder $(M=40.70, S D=8.82)$ compared to individuals without a schizophrenia-spectrum diagnosis $(M=37.38, S D=$ 11.55), $t(296.65)=-2.82, p<.05$. A Pearson bivariate correlation indicated that age was significantly negatively correlated with physical health $r(293)=-.17, p<.01$. Based on the results of these covariate analyses, gender was included as a covariate for the mediating and outcome variables in all analyses; diagnosis was included as a covariate 
THE INFLUENCE OF SENSE OF COMMUNITY

for sense of community, psychological distress, and mental health; and age was included as a covariate in the physical health model.

\section{Mediation Analyses}

All of the hypotheses were tested in SPSS Version 24 (IBM Corporation, 2016) using path analysis-based mediation with the Hayes PROCESS macro (model 4, version 2.16; Hayes, 2013). Mediation analyses may be conducted through several statistical approaches, including regressions proposed by Baron and Kenny, various forms of regression-based bootstrapping, and structural equation modeling (SEM). PROCESS is considered to be preferable to the traditional Baron and Kenny approach because the latter approach requires that there is a significant association between a predictor and outcome variable, even though that is not a necessary condition to provide support for mediation (Hayes, 2013). Additionally, the Baron and Kenny approach does not specifically quantify the indirect effect of a mediating variable and does not conduct any inferential tests directly on the mediation. While structural equation modeling (SEM) was considered as a possible method for analyzing the research questions, PROCESS was ultimately chosen because of the relatively smaller sample size and the lack of theoretical evidence that is required to support using SEM to predict pathway models (Hayes \& Scharkow, 2013). Finally, employing bias-corrected bootstrapping techniques adjusts for any violations of normality or homoscedasticity and tends to be more powerful, especially if an indirect effect exists (Hayes \& Scharkow, 2013). The tests of indirect effects were run with both 5,000 and 10,000 bootstraps for all hypotheses. The standard 
THE INFLUENCE OF SENSE OF COMMUNITY

errors and confidence intervals remained the same after increasing to 10,000 bootstraps;

therefore, results corresponding to the 5,000 bootstraps are reported.

Psychological Distress. In the first mediation model, total number of activities

(i.e., community participation) was indicated as the predictor variable, sense of community as the mediator, and psychological distress as the outcome variable.

Diagnosis and gender were included as covariates for the mediating and outcome variables. Overall, the mediation model was significant, $F(4,290)=13.53, p<.001, R^{2}=$ .16. In support of hypothesis 1a, total number of activities significantly predicted psychological distress $(b=-.02, \beta=-.11, p<.05)$. Results indicated that total number of activities significantly predicted sense of community $(b=.05, \beta=.24, p<.001)$, supporting hypothesis 2 . In support of hypothesis $3 a$, sense of community significantly predicted psychological distress $(b=-.23, \beta=-.26, p<.001)$. A test of the indirect effect of total number of activities on psychological distress through sense of community revealed that total number of activities predicted psychological distress as a function of sense of community (indirect effect $=-.01,95 \%$ BC CI: $[-.02-.01]$ ), which provides support for hypothesis 4a. These results suggest a partial mediation (see Table 6 and Figure 4).

Mental Health. In the second mediation model, total number of activities (i.e., community participation) was indicated as the predictor variable, sense of community as the mediator, and mental health as the outcome variable. Diagnosis and gender were included as covariates for the mediating and outcome variables. Overall, the mediation model was significant, $F(4,291)=10.06, p<.001, R^{2}=.12$. Results indicated that total 
THE INFLUENCE OF SENSE OF COMMUNITY

number of activities significantly predicted mental health $(b=.40, \beta=.13, p<.05)$, thus

supporting hypothesis $1 \mathrm{~b}$. In support of hypothesis 2 , total number of activities

significantly predicted sense of community $(b=.05, \beta=.25, p<.001)$. Next, sense of

community significantly predicted mental health $(b=3.50, \beta=.24, p<.001)$, supporting

hypothesis $3 b$. In support of hypothesis $4 b$, a test of the indirect effect of total number of activities on mental health through sense of community revealed that total number of activities predicted mental health as a function of sense of community (indirect effect $=$ $.19,95 \%$ BC CI: [.09-.35]). Again, these results suggest a partial mediation (see Table 7 and Figure 5).

Physical Health. In the third mediation model, total number of activities (i.e., community participation) was indicated as the predictor variable, sense of community as the mediator, and physical health as the outcome variable. Age and gender were included as covariates for the mediating and outcome variables. Overall, the mediation model was significant, $F(4,287)=7.23, p<.001, R^{2}=.09$. Total number of activities did not significantly predict physical health $(b=.19, \beta=.06, p=.31)$. In support of hypothesis 2 , results indicated that total number of activities significantly predicted sense of community $(b=.05, \beta=.24, p<.001)$. Sense of community significantly predicted physical health $(b=1.65, \beta=.11, p<.05)$. A test of the indirect effect of total number of activities on physical health through sense of community revealed that total numbers of activities predicted physical health as a function of sense of community (indirect effect $=$ $.08,95 \%$ BC CI: [.00-.21]), supporting hypothesis 4c. These results suggest a full 
THE INFLUENCE OF SENSE OF COMMUNITY

mediation, as the community participation variable was no longer a predictor of physical health when sense of community was included in the model (see Table 8 and Figure 6).

\section{Post-hoc analyses}

The role of community participation has only recently been investigated for individuals with serious mental illness, and research has not explored whether it is the frequency or the variety of participation that positively influences recovery. Therefore, additional analyses were conducted to examine the total number of participation days as the operational definition for community participation rather than the total number of activities, as was reported in the analyses above. Total number of days did not significantly predict any of the recovery outcomes, including psychological distress, mental health, and physical health. Additionally, there were no significant tests of indirect effects of total number of days on any outcome variables with sense of community as the mediator. 
THE INFLUENCE OF SENSE OF COMMUNITY

\section{Chapter 5}

\section{Discussion}

Due in large part to the deinstitutionalization movement, the vast majority of people with serious mental illnesses live and receive services in community settings (Townley \& Kloos, 2009). Consequently, community integration has emerged as a priority area among mental health advocates, policy makers, and researchers (Nelson, Lord, \& Ochocka, 2001; Ware, Hopper, Tugenberg, Dickey, \& Fisher, 2007; Yanos, 2007). Finding ways to promote community integration and, ultimately, recovery for adults with serious mental illnesses may be especially important as resources in the community and opportunities for participation in valued social roles continue to be limited. As such, the findings from the current study highlight the importance of community-based factors, particularly community participation and sense of community, in facilitating recovery outcomes for adults with serious mental illnesses.

\section{Overview of Study Findings}

Psychological distress. The primary goal of the present study was to examine sense of community as a potential mediating factor between community participation and psychological distress. As hypothesized, participants who reported higher levels of community participation also reported higher levels of sense of community and lower levels of psychological distress. Additionally, total number of activities (i.e., community participation) remained a significant predictor of psychological distress when sense of community was added to the model, suggesting a partial mediation. Furthermore, the results indicated a significant negative indirect effect, suggesting that sense of community 
THE INFLUENCE OF SENSE OF COMMUNITY

acts a meaningful mediator between community participation and psychological distress.

The results of this mediation analysis suggest that while community participation is important, the feelings of belonging and acceptance from community members also influence psychological distress. Consistent with past research, while being physically present in the community (i.e., physical integration) is likely beneficial to recovery, it is the social and psychological aspects of community integration that primarily results in lower psychological distress (Prince \& Gerber, 2005; Tew et al., 2011; Wong \& Solomon, 2002).

Mental and physical health. The current study also sought to test the role that community factors play in promoting other aspects of recovery, including mental and physical health. In support of the study hypotheses, individuals who reported higher levels of community participation also reported higher levels of sense of community, mental health, and physical health. For the mental health outcome model, total number of activities (i.e., community participation) remained significant after adding sense of community as a mediator, suggesting partial mediation. Nonetheless, there was a significant positive indirect effect of sense of community, indicating that sense of community acts as an important mediator of the relationship between community participation and mental health. Once again, these findings suggest that it is the core components of sense of community (i.e., membership, influence, integration and fulfillment of needs, shared emotional connection) that may be the driving force behind the association between participating in community activities and experiencing more positive mental health (McMillan \& Chavis, 1986). The results of the present study 
THE INFLUENCE OF SENSE OF COMMUNITY

support past research that suggests the positive influence of community-based factors on the mental health of individuals with serious mental illnesses (Kloos \& Townley, 2011; Tsai \& Rosenheck, 2012).

For physical health, total number of activities (i.e., community participation) was not a significant predictor after adding sense of community as a mediator, which suggests that sense of community was completely mediating the relationship between community participation and physical health. There was also a significant positive indirect effect of sense of community, supporting the notion that sense of community acts an important mediator between community participation and physical health. Interestingly, the physical health model was the only mediation model that produced a full mediation, such that community participation was not a significant predictor of physical health with sense of community as the mediator. While it has been well documented that there are many social factors that negatively influence physical health for people with serious mental illnesses (e.g., social isolation, reduced social networks), less is known about the role of sense of community in improving physical health for this population (Hawkley \& Cacioppo, 2010; Lawrence \& Kisely, 2010; Robson \& Gray, 2006). Furthermore, while past research has shown that moderate-vigorous exercise interventions positively impact mental and physical health, research has yet to examine the role that daily and incidental activities play in improving mental and physical health for individuals with serious mental illnesses (Richardson et al., 2005; Ross \& McGuire, 2011). Further research is clearly warranted, but the results of this study suggest that the social and psychological 
THE INFLUENCE OF SENSE OF COMMUNITY

benefits of sense of community may be particularly important in explaining the associations between community participation and health.

Total number of participation days. An exploratory aspect of the present study was to investigate whether different indicators of community participation also positively influenced recovery outcomes for adults with serious mental illnesses. Therefore, total number of participation days replaced total number of activities as the operational definition of community participation, and the same mediation analyses were conducted. The results of these analyses revealed that while total number of participation days significantly predicted sense of community, total number of participation days did not significantly predict psychological distress, mental health, or physical health. Furthermore, sense of community did not act as a significant mediator between total number of participation days and any of the recovery outcomes. Therefore, the frequency of participation may be an important indicator of sense of community, but the number of participation days does not significantly relate to recovery outcomes. Participants who reported more participation days may have been performing the same activity many times over 30 days. For example, a person who took public transportation every day would report high numbers of participation days, but may not participate in any other activity. While the activity may have helped to foster a sense of community, it may not have been strong enough to influence psychological distress, mental health, or physical health. For improvements in health outcomes, the preliminary suggestion from this study is that the variety of participation (i.e., engagement in a larger number of different activity areas) may be more important than the frequency of participation. More research is needed to 
THE INFLUENCE OF SENSE OF COMMUNITY

further unpack this finding, including examining potential moderators such as health. For example, a person who is physically disabled may not be able to participate in a greater variety of activities but likely still benefits from the sense of community developed in the few activities they do participate in regularly.

\section{Limitations and Future Research Directions}

While this study has numerous strengths, several limitations must also be noted.

First, this study may not be generalizable to all adults with serious mental illnesses because participants were voluntarily recruited from outpatient mental health services organizations. These participants may have experiences that are quite different from those who are not engaged in outpatient mental health services. Further, while the current study improves upon previous research by recruiting individuals with serious mental illnesses from a variety of urban and non-urban locations across the United States, results may not be generalizable to individuals living outside the US, particularly in non-Western countries.

Second, although empirical research supports using sense of community as a mediating variable (Prince \& Gerber, 2005), theoretical discussions argue that the relationship between sense of community and community participation is circular in nature; therefore, it may be that sense of community predicts community participation in addition to the reverse (Talò, Mannarini, \& Rochira, 2014). Future research is needed to continue to examine how the relationship between community participation and sense of community operates in different contexts and for different populations. 
THE INFLUENCE OF SENSE OF COMMUNITY

The criterion for establishing causality includes covariation between variables, temporal ordering, and elimination of competing explanations (Hayes, 2013; Kline, 2015). The data collected in this study is cross-sectional and observational in design, and therefore can only be used to establish covariation between variables. However, theory suggests that community participation initiates a stronger sense of community, which in turn reduces psychological distress and promotes mental and physical health (Chavis, Hogge, McMillan, \& Wandersman, 1986; Prince \& Gerber, 2005). Future research in the community mental health field should utilize research designs that allow researchers to establish more certain causal associations, such as experimental manipulation of community participation or longitudinal designs (Hayes, 2013).

Additionally, analyses assume that there are no confounders influencing any pair of variables (Kline, 2015). However, it is likely that other factors influence the associations between these variables (McMillan \& Chavis, 1990; Prince \& Gerber, 2005). For example, current age, age of diagnosis, and length of service use may be important indicators of community participation, sense of community, and recovery. Data on these possible demographic confounds were not collected in the present study. People with serious mental illnesses who were diagnosed many years ago may be more likely to participate in community activities and feel a sense of belonging to their community than individuals who have been recently diagnosed. Additionally, these individuals may have spent more time in therapy, been prescribed certain treatment regimens, and may have developed better coping strategies that influence their community participation and recovery outcomes. However, while research suggests that people with serious mental 
THE INFLUENCE OF SENSE OF COMMUNITY

illnesses do recover over time (Harding, 1994), qualitative reports continue to show that mental health recovery requires on-going maintenance and attention which significantly influences the types and frequency of participation that occurs (Dewees, Pulice, \& McCormick, 1996). Future research should measure these potential confounders and account for them in analyses.

In addition, while the current study recruited individuals from both urban and non-urban locations in the United States, the statistical analyses did not differentiate participants by location. Interestingly, research utilizing the same dataset found that participants in urban areas reported higher levels of community participation than participants in non-urban areas (Townley, Brusilovskiy, \& Salzer, 2017). Furthermore, the researchers found that participants in urban areas also reported higher levels of sense of community than participants in non-urban areas (Townley, Brusilovskiy, \& Salzer, 2017). Therefore, it is possible that recovery outcomes may also differ between individuals in urban versus non-urban areas, and future research should examine these potential differences.

A strength of the current study is that individuals with serious mental illnesses contributed to the development of the scale used to measure community participation, the TUCP. Further, the TUCP recognizes that interpersonal relationships, major life activities, and social, community, and civic life play important roles in recovery, moving beyond the traditional examination of only participation in the domestic life domain (Salzer et al., 2014). While this study focused on independent participation (i.e., activities done without the assistance of mental health staff), it did not differentiate between 
THE INFLUENCE OF SENSE OF COMMUNITY

activities performed with other adults who have mental illnesses and those performed with individuals who do not have a disability. While community integration research has often emphasized the importance of participation in activities that are separated from other individuals who have disabilities, other researchers and advocates have argued that definitions of participation should highlight the value of engaging with peers of one's own choosing, which may certainly involve other individuals with disabilities (Cummins \& Lau, 2003; Milner \& Kelly, 2009; Pinfold, 2002). Future research should further examine the types of individuals with whom participation occurs and how this may differentially affect recovery.

Additionally, while this current study used mediation analyses with data from all participants combined, it would be interesting to assess whether the individuals in the sample fall into different categories of participation. The measurement of participation included many different types of participation, such as taking public transportation, employment, and participating in volunteer activities. Future research should consider examining differences between individuals who mostly complete activities of daily living (e.g., running errands) compared to activities that may be more social or voluntary (e.g., volunteering). Latent class analysis or cluster analysis could also be conducted to empirically examine whether participants fall into different subgroups depending on their type and frequency of participation across various activity domains.

Furthermore, it is important to consider that even though adults with serious mental illnesses may have opportunities to participate in their communities, there may be individual barriers to community participation, including symptom distress, physical 
THE INFLUENCE OF SENSE OF COMMUNITY

disabilities, or physical illnesses that may be untreated due to inadequate access to healthcare. Perhaps even more influential, there are social, political, and cultural factors that may prohibit people from participating fully in their communities, including lower socioeconomic status, lack of employment opportunities, transportation barriers, and mental health stigma (Dewees, Pulice, \& McCormick, 1996). These factors are likely to also influence recovery (Harding, Zubin, \& Strauss, 1987). Finally, it is important to recognize that individuals may choose not to actively participate in their communities and may foster a sense of community by spending time with family members or engaging with online communities (Brusilovskiy, Townley, Snethen, \& Salzer, 2016). These individual and contextual variables should be the focus of future research aimed at better understanding the complex association between community participation, sense of community, and recovery for individuals with serious mental illnesses.

\section{Implications for Research and Practice}

The current study has important implications that contribute to the field of community mental health research and practice. The findings are consistent with the notion that community-based factors, such as community participation and sense of community, are positively associated with recovery outcomes for people with serious mental illnesses (Kloos \& Townley, 2011; Prince \& Gerber, 2005). Specifically, community participation, measured by the total number of activities in which they engage, was significantly related to recovery of individuals with serious mental illness through their increased perceptions of sense of community. While several scholars have discussed the relationship between community participation and sense of community over 
THE INFLUENCE OF SENSE OF COMMUNITY

the years, research has yet to explicitly explore the potentially directional relationship between the two constructs. However, both Chavis et al. (1986) and Prince and Gerber (2005) have posited that community participation is likely to lead to an increase in sense of community. While longitudinal research is needed to confirm the direction of effects, the current study provides provisional evidence that community participation may in fact influence sense of community, and in turn, recovery for individuals with serious mental illnesses.

Interestingly, the results of covariate analyses found that individuals who were diagnosed with a schizophrenia-spectrum disorder reported higher levels of sense of community and mental health, and lower levels of psychological distress compared to individuals without a schizophrenia-spectrum diagnosis. These results suggest that these individuals are experiencing more sense of community, better mental health, and less psychological distress than individuals who are not diagnosed with a schizophreniaspectrum disorder. There is currently a gap in the literature regarding the influence of the type of mental health diagnosis on community-based factors and recovery outcomes. As such, future research should continue to explore the ways that individuals with different mental health diagnoses may experience these constructs.

Additionally, the present study contributed to the current literature by adding important aspects of recovery, specifically mental health and physical health, as the outcomes of interest. Although past research has acknowledged that these factors may be important to the recovery of people with serious mental illnesses (Salyers et al., 2000; Whitley \& Drake, 2010), this study was one of the first steps in understanding how 
THE INFLUENCE OF SENSE OF COMMUNITY

community participation and sense of community could influence mental and physical health. Future research should continue to investigate the role that community factors play in promoting health outcomes beyond traditional measures of psychological distress or symptom management.

Furthermore, the current study provides additional evidence supporting the reliability, validity, and use of the recently developed Temple University Community Participation Measure (TUCP; Salzer, Brusilovskiy, Prvu-Bettger, \& Kottsieper 2014). Specifically, the current study examined whether the total number of activities or the total number of participation days were more predictive of sense of community and recovery. Results indicate that while total number of activities significantly predicted sense of community and recovery outcomes, total number of participations days did not. Furthermore, the association between total number of participation days and recovery outcomes, with sense of community as a mediator of this relationship, was not supported. Future research should continue to examine which components of the community participation construct are most beneficial for adults with serious mental illnesses. This may also be done by focusing exclusively on types of participation that are indicated as being most important or relevant to members of this population. For example, BurnsLynch, Brusilovskiy, and Salzer (2016) discovered that participants who perceived that they participated in important activities a sufficient amount (e.g., going to a movie or going to a religious organization as often as they wanted to) reported higher levels of recover and quality of life compared to participants who reported insufficient amounts of activity. 


\section{THE INFLUENCE OF SENSE OF COMMUNITY}

As community mental health research, policy, and practice continues to move beyond symptom management and toward a more holistic understanding of recovery, the results of the current study reflect Anthony's (1993) recovery-oriented approach by including more global measures of mental and physical health as outcome variables. Although symptom management remains a fundamental aspect of community mental health services, finding alternative ways to promote recovery that are rooted in community spaces may help offset the many challenges faced by mental health service organizations, including lack of funding, high client caseloads, and service provider burnout (Davidson, O’Connell, Tondora, Styron, \& Kangas, 2002). As adults with serious mental illnesses become more fully integrated into the community and experience increased recovery, they may become less reliant on community mental health services. This would allow community mental health service providers to reduce caseload sizes and spend more time supporting individuals who require more assistance with symptom management and adaptive functioning (Davidson et al., 2002).

The results of the current study also inform future interventions that aim to promote community integration among adults with serious mental illnesses. For instance, interventions that promote community participation have been found to benefit individuals more effectively than clinical services alone (Segal, Silverman, \& Temkin, 2010). Thus, interventions and social programs that encourage community participation, and in turn foster a sense of community, may be more successful in mobilizing efforts and enacting transformative change within service agencies and communities (McMillan \& Chavis, 1990; Nelson, Kloos, \& Ornelas, 2014). 


\section{THE INFLUENCE OF SENSE OF COMMUNITY}

\section{Conclusion}

The results of this study suggest that community factors play an important role in recovery outcomes for individuals with serious mental illnesses. Specifically, sense of community acts as a mediator of the relationship between community participation and each of the following indicators of well-being: psychological distress, mental health, and physical health. Therefore, while participating in community activities is important, it is the feeling that one belongs to and is accepted by a larger group of individuals that may impact important recovery outcomes. These findings highlight the fact that is it important for individuals with serious mental illnesses to both be in the community and also of the community, with meaningful opportunities to engage in activities, establish relationships with others, and develop feelings of belongingness and acceptance (Cummins \& Lau, 2003; Ware et al., 2007). As such, policy and practices should continue to strive to find ways to promote community integration for people with serious mental illnesses as they actively work towards recovery. 
THE INFLUENCE OF SENSE OF COMMUNITY

Table 1

Descriptive Statistics

\begin{tabular}{|c|c|c|c|c|c|c|c|c|c|}
\hline \multirow{2}{*}{ Measure } & \multirow{2}{*}{$\mathrm{N}$} & \multirow{2}{*}{ Min } & \multirow{2}{*}{ Max } & \multirow{2}{*}{ Mean } & \multirow{2}{*}{ SD } & \multicolumn{2}{|c|}{ Skewness } & \multicolumn{2}{|c|}{$\underline{\text { Kurtosis }}$} \\
\hline & & & & & & Statistic & SE & Statistic & SE \\
\hline $\begin{array}{l}\text { Community } \\
\text { Participation - } \\
\text { Total number } \\
\text { of activity days }\end{array}$ & 299 & 0 & 238 & 50.58 & 40.32 & 1.59 & .14 & 3.52 & .28 \\
\hline $\begin{array}{c}\text { Community } \\
\text { Participation - }\end{array}$ & & & & & & & & & \\
\hline $\begin{array}{l}\text { Total number } \\
\text { of activities }\end{array}$ & 299 & 0 & 22 & 7.56 & 3.41 & .64 & .14 & .54 & .28 \\
\hline $\begin{array}{c}\text { Sense of } \\
\text { Community }\end{array}$ & 300 & 1 & 4 & 2.43 & .74 & .23 & .14 & -.70 & .28 \\
\hline $\begin{array}{c}\text { Psychological } \\
\text { Distress }\end{array}$ & 298 & 1 & 4 & 2.09 & .65 & .33 & .14 & -.36 & .28 \\
\hline $\begin{array}{l}\text { Physical } \\
\text { Health }\end{array}$ & 298 & 17 & 69 & 44.54 & 10.72 & -.14 & .14 & -.76 & .28 \\
\hline Mental Health & 299 & 13 & 71 & 38.79 & 10.59 & .00 & .14 & -.16 & .28 \\
\hline
\end{tabular}


THE INFLUENCE OF SENSE OF COMMUNITY

Table 2

Intraclass Correlation Coefficients for Primary Study Variables at Mental Health Organization and State Levels

\begin{tabular}{lll}
\hline Study Variable & ICC - Organization level & ICC - State level \\
\hline $\begin{array}{l}\text { Community Participation - } \\
\text { Total number of activities }\end{array}$ & 0.03 & 0.04 \\
$\begin{array}{l}\text { Community Participation - } \\
\text { Total number of participation }\end{array}$ & 0.06 & 0.05 \\
days & & \\
Sense of Community & 0.04 & \\
Psychological Distress & 0.06 & 0.05 \\
Mental Health & 0.02 & 0.07 \\
Physical Health & 0.04 & 0.00 \\
\hline
\end{tabular}

Note. Organization level, $\mathrm{n}=21$; state level, $\mathrm{n}=15$ 
THE INFLUENCE OF SENSE OF COMMUNITY

Table 3

Correlation Matrix of Study Variables

\begin{tabular}{|c|c|c|c|c|c|c|}
\hline & $\begin{array}{l}\text { Community } \\
\text { Participation } \\
\text { - Total } \\
\text { number of } \\
\text { activity days }\end{array}$ & $\begin{array}{c}\text { Community } \\
\text { Participation - } \\
\text { Total number of } \\
\text { activities } \\
\end{array}$ & $\begin{array}{c}\text { Sense of } \\
\text { Community }\end{array}$ & $\begin{array}{c}\text { Psychological } \\
\text { Distress }\end{array}$ & $\begin{array}{c}\text { Physical } \\
\text { Health }\end{array}$ & $\begin{array}{l}\text { Mental } \\
\text { Health }\end{array}$ \\
\hline $\begin{array}{l}\text { Community } \\
\text { Participation - } \\
\text { Total number } \\
\text { of activity days }\end{array}$ & -- & & & & & \\
\hline $\begin{array}{l}\text { Community } \\
\text { Participation - } \\
\text { Total number } \\
\text { of activity } \\
\text { areas }\end{array}$ & $.66 * *$ & & & & & \\
\hline $\begin{array}{l}\text { Sense of } \\
\text { Community }\end{array}$ & $.18^{* *}$ & $.25^{* *}$ & & & & \\
\hline $\begin{array}{l}\text { Psychological } \\
\text { Distress }\end{array}$ & -.11 & $-.18 * *$ & $-.32 * *$ & & & \\
\hline $\begin{array}{l}\text { Physical } \\
\text { Health }\end{array}$ & $.11 *$ & .10 & $.17 * *$ & $-.35 * *$ & & \\
\hline Mental Health & $.14^{*}$ & $.18^{* *}$ & $.31 * *$ & $-.61 * *$ & -.04 & -- \\
\hline
\end{tabular}




\section{THE INFLUENCE OF SENSE OF COMMUNITY}

Table 4

Independent Samples T-Test: Outcome Variables by Gender

\begin{tabular}{|c|c|c|c|c|c|c|c|c|c|c|}
\hline & \multicolumn{3}{|c|}{ Female } & \multicolumn{3}{|c|}{ Male } & \multirow[b]{2}{*}{$\mathrm{t}$} & \multirow[b]{2}{*}{ df } & \multicolumn{2}{|c|}{$95 \% \mathrm{CI}$} \\
\hline & M & SD & $\mathrm{n}$ & M & $\mathrm{SD}$ & $\mathrm{n}$ & & & Lower & Upper \\
\hline $\begin{array}{l}\text { Sense of } \\
\text { Community }\end{array}$ & 2.33 & 0.73 & 179 & 2.58 & 0.74 & 119 & $-2.87 *$ & 296 & -.42 & -.08 \\
\hline $\begin{array}{l}\text { Psychological } \\
\text { Distress }\end{array}$ & 2.23 & 0.65 & 178 & 1.89 & 0.60 & 118 & $4.50 *$ & 294 & 0.19 & 0.49 \\
\hline Physical Health & 42.73 & 11.21 & 178 & 47.17 & 9.41 & 118 & $-3.68 *$ & 278.08 & -6.81 & -2.06 \\
\hline Mental Health & 37.85 & 10.65 & 179 & 40.35 & 10.29 & 118 & $-2.01 *$ & 295 & -4.96 & -0.06 \\
\hline
\end{tabular}

Note. $* p<.05$ 
THE INFLUENCE OF SENSE OF COMMUNITY

Table 5

Independent Samples T-Test: Outcome Variables by Diagnosis

\begin{tabular}{|c|c|c|c|c|c|c|c|c|c|c|}
\hline & \multicolumn{3}{|c|}{$\begin{array}{l}\text { Schizophrenia - } \\
\text { Spectrum (No) }\end{array}$} & \multicolumn{3}{|c|}{$\begin{array}{l}\text { Schizophrenia - } \\
\text { Spectrum (Yes) }\end{array}$} & \multirow[b]{2}{*}{$\mathrm{t}$} & \multirow[b]{2}{*}{ df } & \multicolumn{2}{|c|}{$\underline{95 \% \mathrm{CI}}$} \\
\hline & $\mathrm{M}$ & $\mathrm{SD}$ & $\mathrm{n}$ & $\mathrm{M}$ & $\mathrm{SD}$ & $\mathrm{n}$ & & & Lower & Upper \\
\hline $\begin{array}{l}\text { Sense of } \\
\text { Community }\end{array}$ & 2.33 & 0.71 & 172 & 2.56 & 0.76 & 128 & $-2.64 *$ & 298 & -.40 & -.06 \\
\hline $\begin{array}{l}\text { Psychological } \\
\text { Distress }\end{array}$ & 2.16 & .67 & 172 & 2.00 & .62 & 126 & $2.10^{*}$ & 296 & .10 & .31 \\
\hline Mental Health & 37.38 & 11.55 & 172 & 40.70 & 8.82 & 127 & $-2.82 *$ & 296.65 & -5.64 & -1.00 \\
\hline
\end{tabular}

Note. $* p<.05$. 


\section{THE INFLUENCE OF SENSE OF COMMUNITY}

Table 6

Summary of Mediation Model 1, with Psychiatric Distress as the Outcome

Direct Effects of Community Participation on Psychological Distress

\begin{tabular}{llccc} 
& & \multicolumn{2}{c}{ Psychological Distress } \\
\hline Predictor & $\mathrm{b}(\mathrm{SE})$ & $\beta$ & $\mathrm{t}$ & $\mathrm{p}$ \\
\hline Intercept & $2.93(.13)$ & -.01 & 22.17 & .00 \\
Sense of Community & $-0.23(.05)$ & -.26 & -4.55 & .00 \\
Community & & & & .05 \\
Participation & $-.02(.01)$ & -.11 & -1.93 & .47 \\
Diagnosis & & & & \\
& $-.05(.07)$ & -.04 & -.72 & .00 \\
\hline
\end{tabular}

Indirect Effect of Community Participation on Psychological Distress Through Sense of Community

\begin{tabular}{lllll} 
& Est. & SE & BootLLCI & BootUCLI \\
\hline $\begin{array}{l}\text { Sense of } \\
\text { Community }\end{array}$ & -.01 & .00 & -.02 & -.01 \\
\hline Note. Indirect effect based on 5,000 bootstraps. Eight cases were excluded due to missing data.
\end{tabular}




\section{THE INFLUENCE OF SENSE OF COMMUNITY}

Table 7

Summary of Mediation Model 2, with Mental Health as the Outcome

Direct Effects of Community Participation on Mental Health

\begin{tabular}{lrrrr} 
& \multicolumn{3}{c}{ Mental Health } \\
\hline Predictor & $\mathrm{b}(\mathrm{SE})$ & $\beta$ & $\mathrm{t}$ & $\mathrm{p}$ \\
\hline Intercept & $26.02(2.17)$ & .01 & 12.01 & .00 \\
Sense of Community & $3.50(.82)$ & .24 & 4.25 & .00 \\
Community & & & & .25 \\
Participation & $.40(.18)$ & .13 & .03 \\
Diagnosis & $2.38(1.21)$ & .11 & 1.96 & .05 \\
Gender & $.93(1.22)$ & .04 & .76 & .45 \\
\hline
\end{tabular}

Indirect Effect of Community Participation on Mental Health Through Sense of Community

\begin{tabular}{lrrrr} 
& Est. & SE & BootLLCI & \multicolumn{2}{c}{ BootUCLI } \\
\hline Sense of Community & .19 & .06 & .09 & .35 \\
\hline
\end{tabular}

Note. Indirect effect based on 5,000 bootstraps. Seven cases were excluded due to missing data. 


\section{THE INFLUENCE OF SENSE OF COMMUNITY}

Table 8

Summary of Mediation Model 3, with Physical Health as the Outcome

Direct Effects of Community Participation on Physical Health

\begin{tabular}{|c|c|c|c|c|}
\hline & & \multicolumn{3}{|c|}{ Physical Health } \\
\hline Predictor & $\mathrm{b}(\mathrm{SE})$ & $\beta$ & $\mathrm{t}$ & $\mathrm{p}$ \\
\hline Intercept & $44.58(3.45)$ & .00 & 12.91 & .00 \\
\hline Sense of Communi & $1.65(.85)$ & .11 & 1.94 & .05 \\
\hline \multicolumn{5}{|l|}{ Community } \\
\hline Participation & $.19(.18)$ & .06 & 1.01 & .31 \\
\hline Age & $-.15(.05)$ & -.16 & -2.85 & .00 \\
\hline Gender & $4.11(1.25)$ & .19 & 3.30 & .00 \\
\hline Indirect Effect of C & tion on Physic & th Throug & Sense of Comr & nity \\
\hline & Est. & SE & BootLLCI & BootUCLI \\
\hline $\begin{array}{l}\text { Sense of } \\
\text { Community }\end{array}$ & .08 & .05 & .00 & .21 \\
\hline
\end{tabular}




\section{THE INFLUENCE OF SENSE OF COMMUNITY}

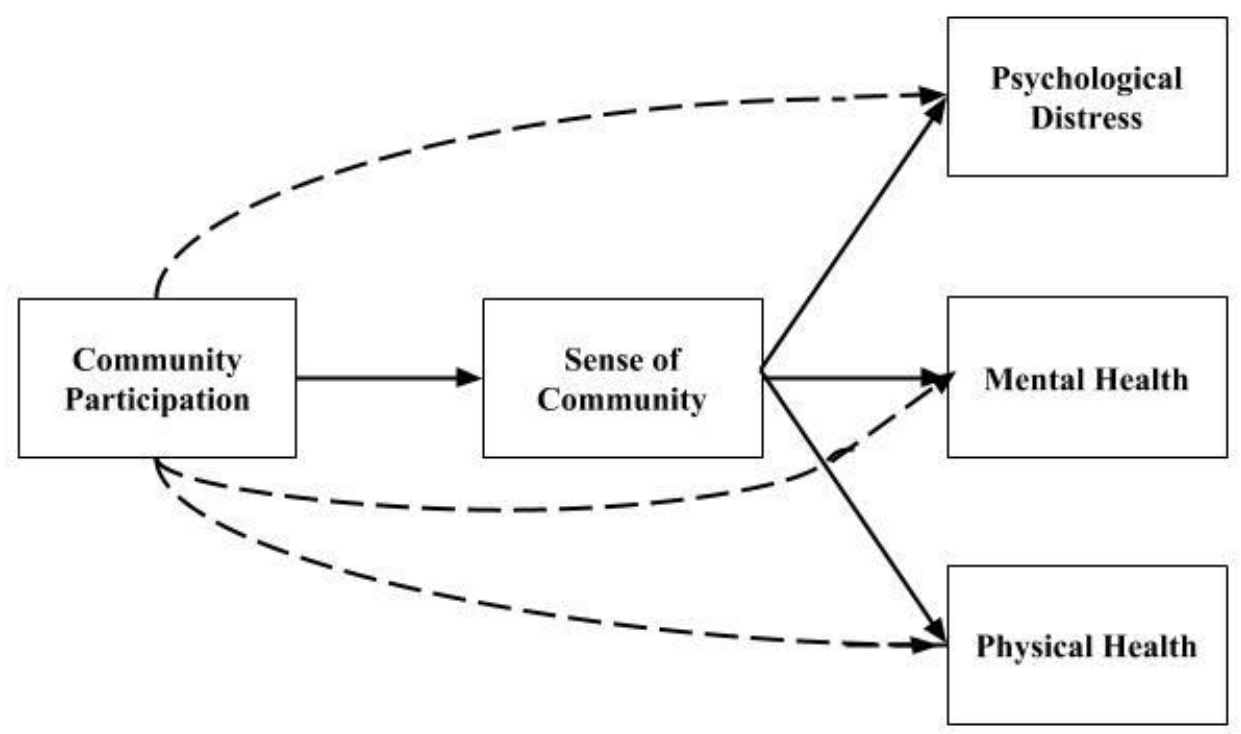

Figure 1. Conceptual model of the proposed mediation analyses. 


\section{THE INFLUENCE OF SENSE OF COMMUNITY}

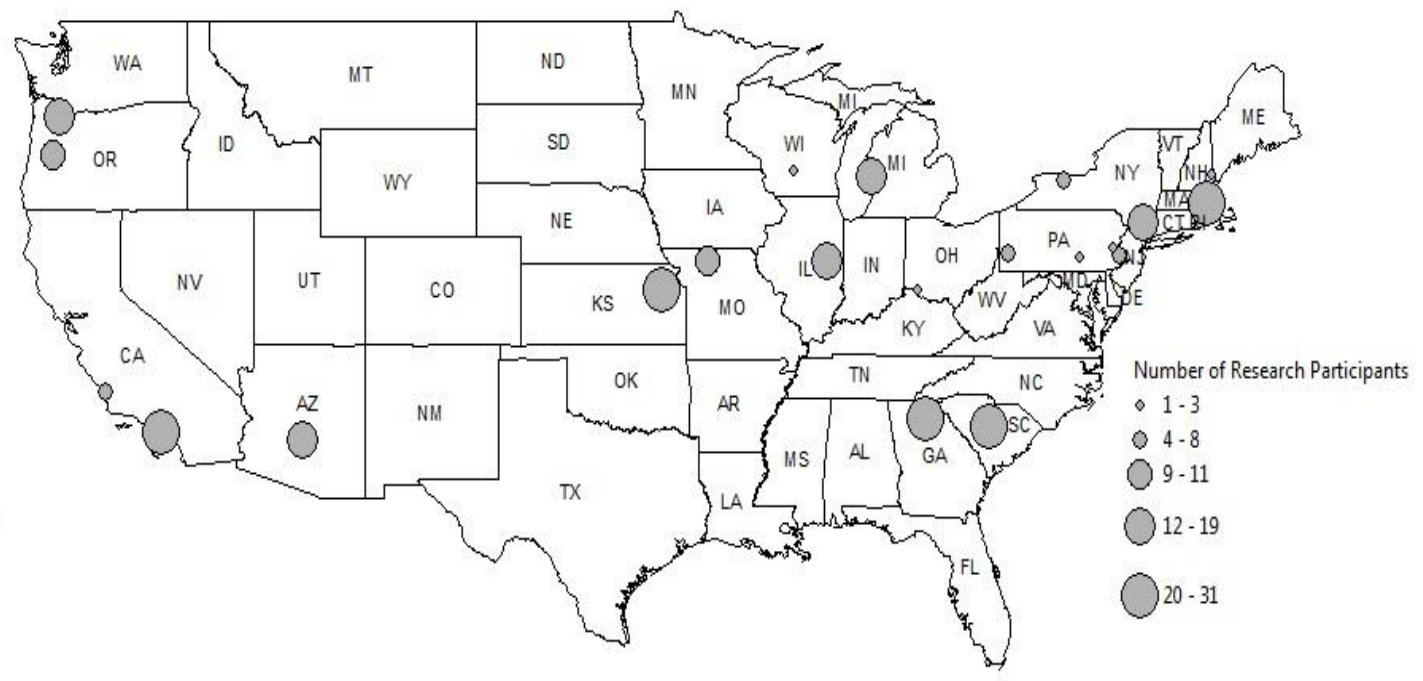

Figure 2. Location of partnering community mental health organizations with participant recruitment totals. 
THE INFLUENCE OF SENSE OF COMMUNITY

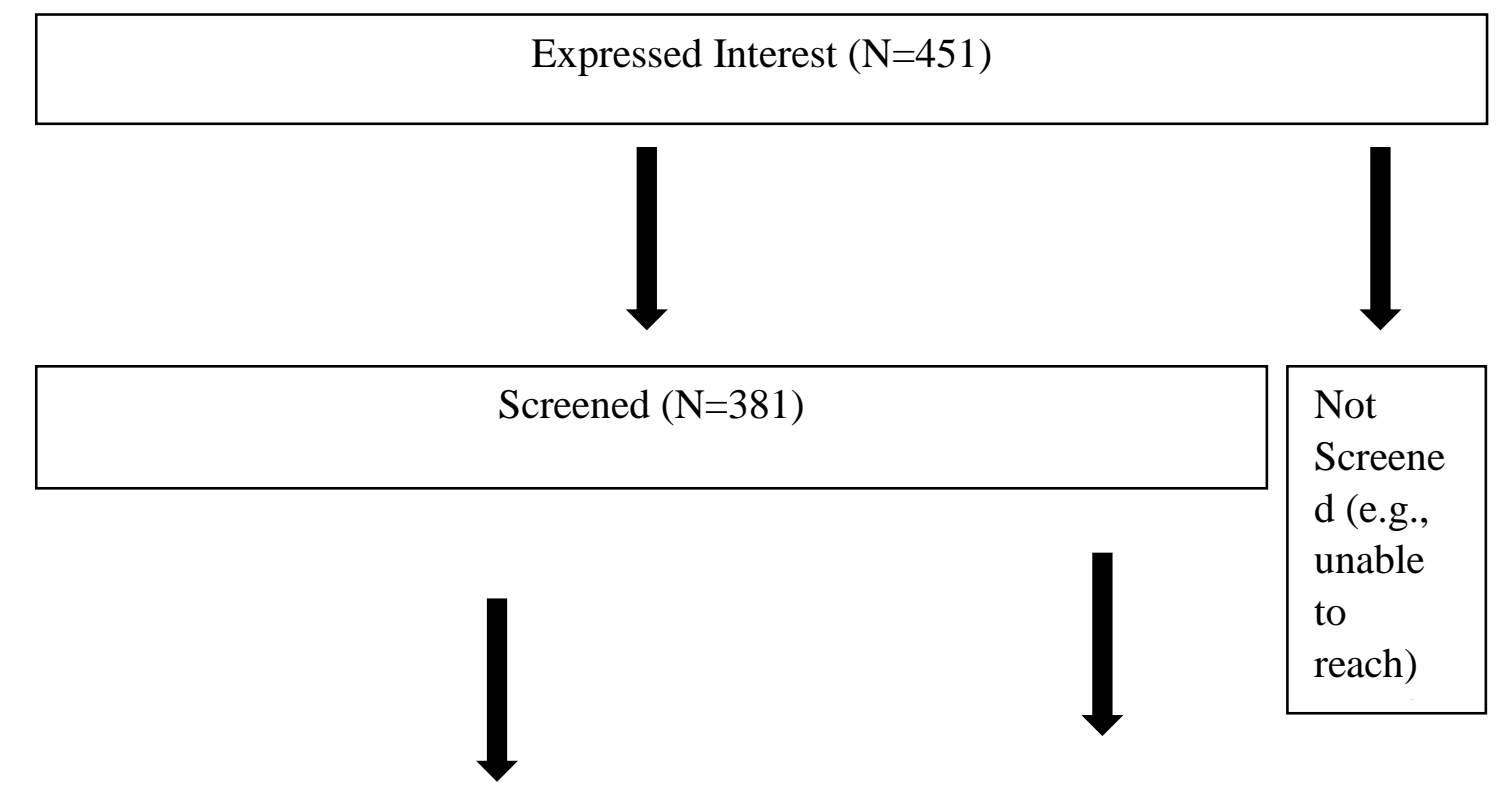

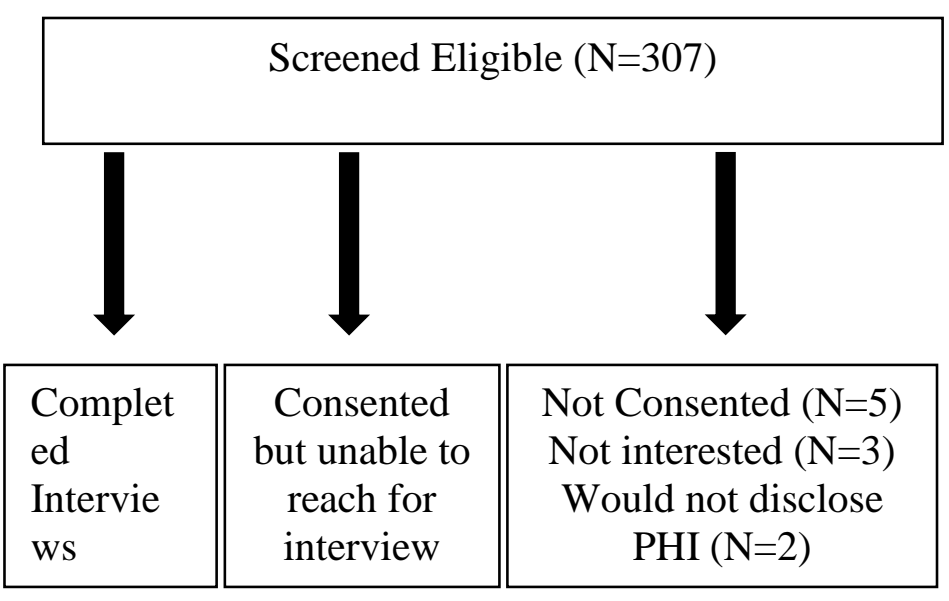

Figure 3. Participant recruitment flow chart.

\begin{tabular}{|c|}
\hline Screened \\
Ineligible \\
$(\mathrm{N}=74)$ \\
\\
No current \\
diagnosis \\
$(\mathrm{N}=8)$ \\
No limitations \\
ever $(\mathrm{N}=29)$ \\
No limitations \\
in past 12 \\
months $(\mathrm{N}=17)$ \\
No \\
Medicaid/care \\
( $\mathrm{N}=11)$ \\
\hline
\end{tabular}




\section{THE INFLUENCE OF SENSE OF COMMUNITY}

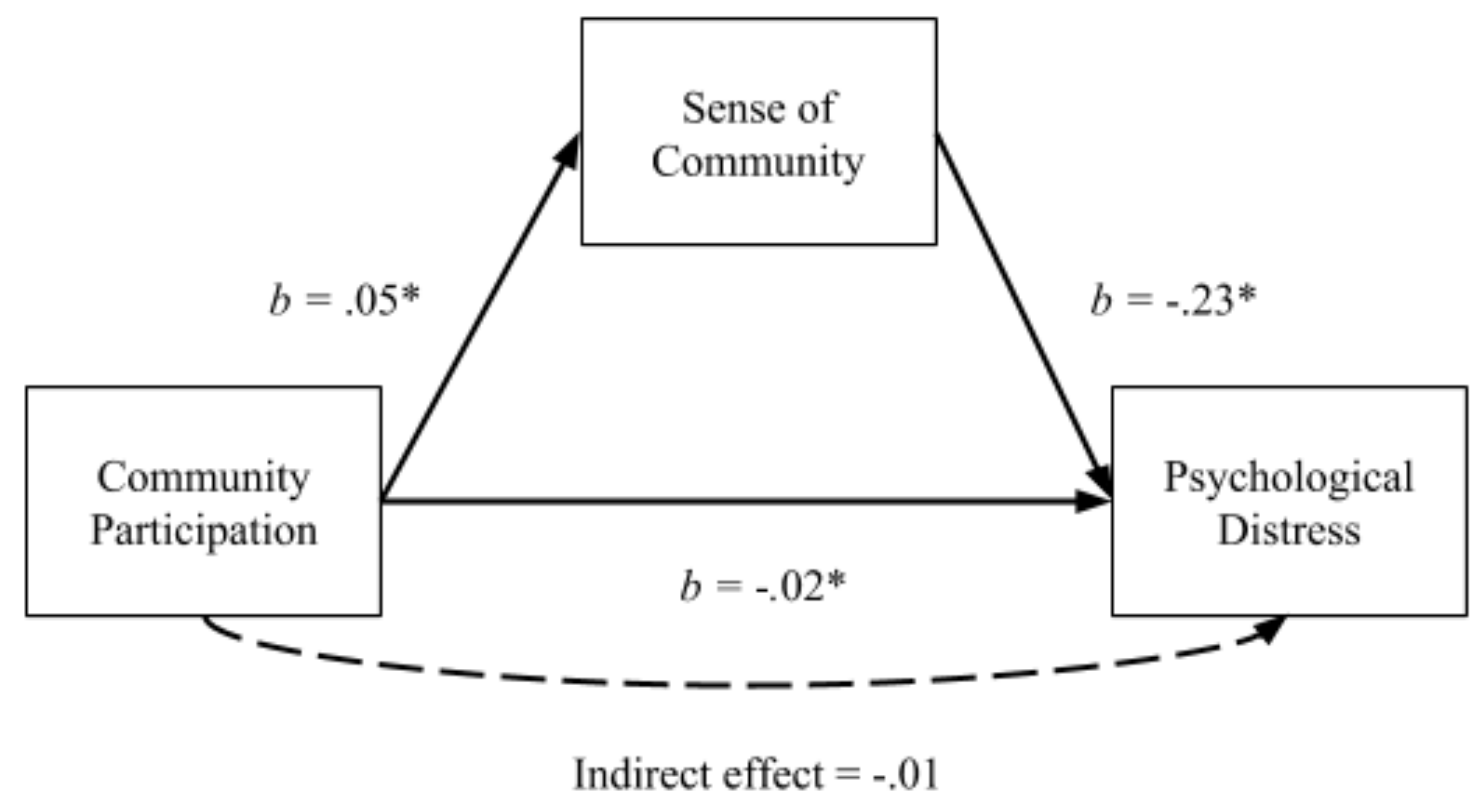

Figure 4. Statistical model of the mediation analysis with psychological distress as an outcome. 
THE INFLUENCE OF SENSE OF COMMUNITY

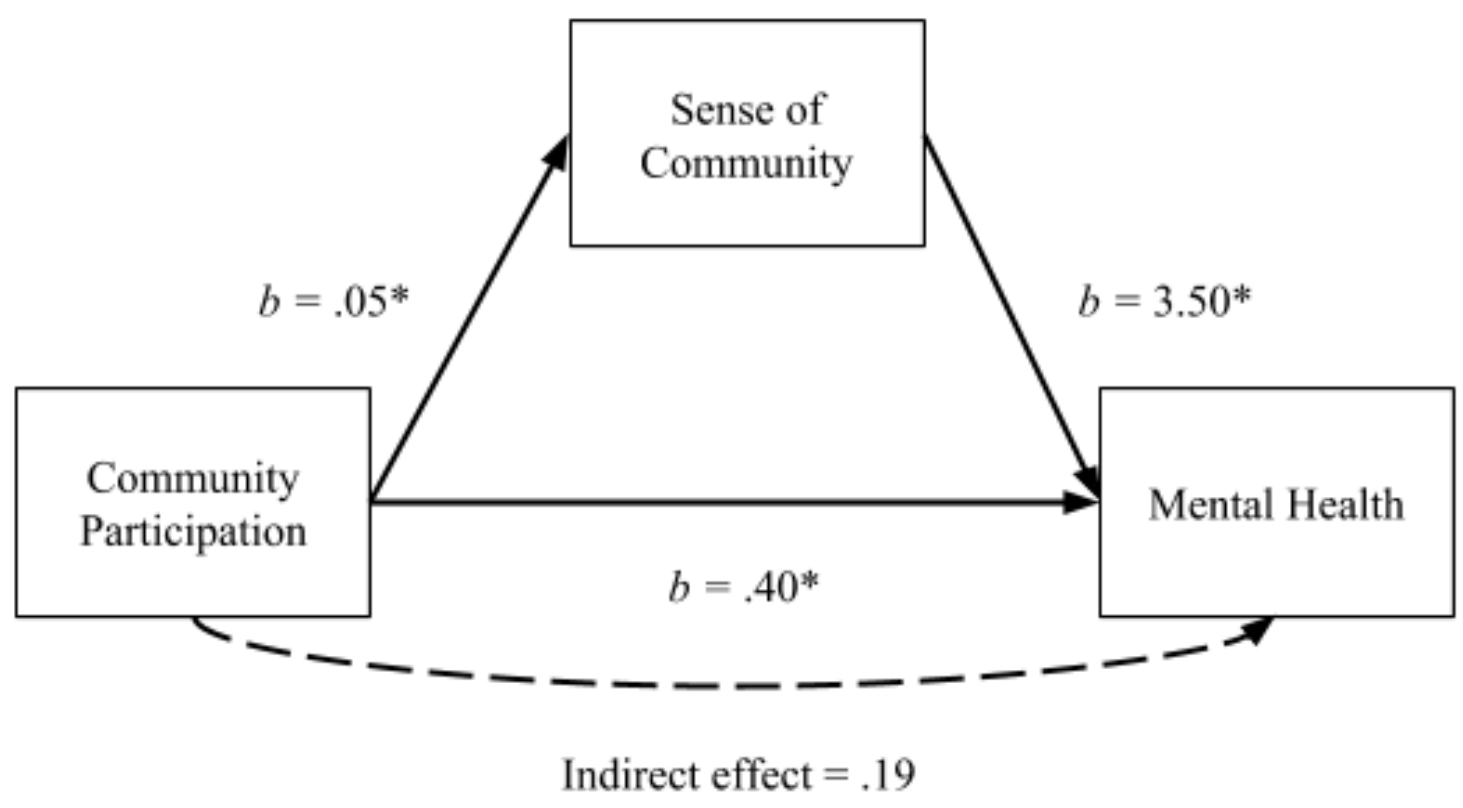

Figure 5. Statistical model of the mediation analysis with mental health as an outcome. 


\section{THE INFLUENCE OF SENSE OF COMMUNITY}

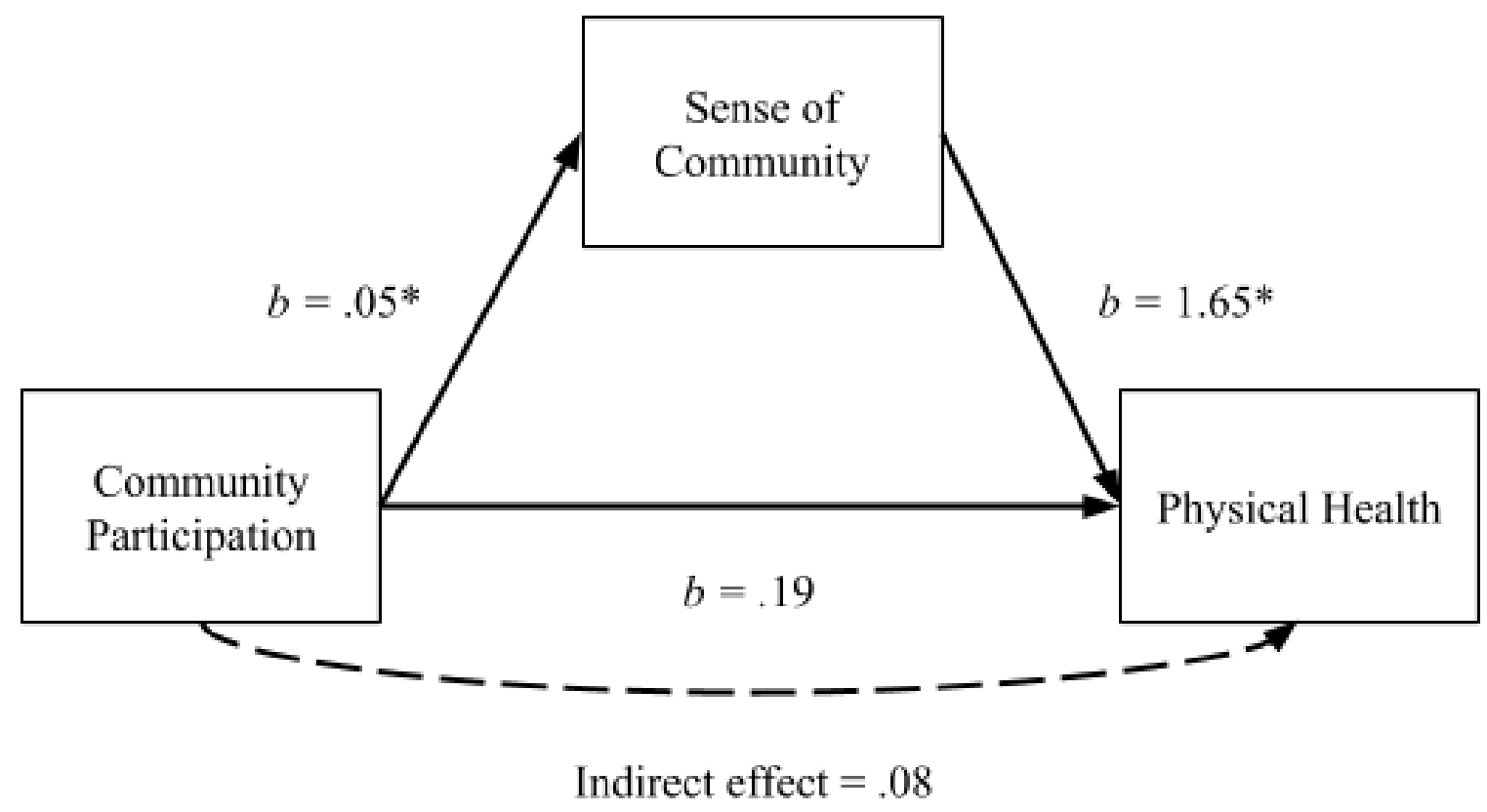

Figure 6. Statistical model of the mediation analysis with physical health as an outcome. 


\section{THE INFLUENCE OF SENSE OF COMMUNITY}

\section{References}

Abdallah, C., Cohen, C. I., Miguel Sanchez-Almira, M. D., Reyes, P., \& Ramirez, P. (2009). Community integration and associated factors among older adults with schizophrenia. Psychiatric Services, 60(12), 1642-1648.

Anthony, W. A. (1993). Recovery from mental illness: The guiding vision of the mental health service system in the 1990s. Psychosocial Rehabilitation Journal, 16(4), 11.

Anthony, W. A. (2000). A recovery-oriented service system: Setting some system level standards. Psychiatric Rehabilitation Journal, 24(2), 159.

Badger, T. A., McNiece, C., Bonham, E., Jacobson, J., \& Gelenberg, A. J. (2003). Health outcomes for people with serious mental illness: A case study. Perspectives in Psychiatric Care, 39(1), 23-32.

Berkman, L. F., Glass, T., Brissette, I., \& Seeman, T. E. (2000). From social integration to health: Durkheim in the new millennium. Social Science \& Medicine, 51(6), 843-857.

Brusilovskiy, E., \& Salzer, M. S. (2012). A study of environmental influences on the well-being of individuals with psychiatric disabilities in Philadelphia, PA. Social Science \& Medicine, 74(10), 1591-1601.

Brusilovskiy, E., Townley, G., Snethen, G., \& Salzer, M. S. (2016). Social media use, community participation and psychological well-being among individuals with serious mental illnesses. Computers in Human Behavior, 65, 232-240.

Burns-Lynch, B., Brusilovskiy, E., \& Salzer, M. S. (2016). An empirical study of the 


\section{THE INFLUENCE OF SENSE OF COMMUNITY}

relationship between community participation, recovery, and quality of life of individuals with serious mental illnesses. Israel Journal of Psychology, 53(1), 46-

55.

Carling, P.J. (1995). Return to Community: Building Support Systems for People with Psychiatric Disabilities. Guilford Press.

Chavis, D. M., Hogge, J. H., McMillan, D. W., \& Wandersman, A. (1986). Sense of community through Brunswik's lens: A first look. Journal of Community Psychology, 14(1), 24-40.

Chavis, D. M., \& Wandersman, A. (1990). Sense of community in the urban environment: A catalyst for participation and community development. American Journal of Community Psychology, 18(1), 55-81.

Colton, C. W., \& Manderscheid, R. W. (2006). Congruencies in increased mortality rates, years of potential life lost, and causes of death among public mental health clients in eight states. Preventing Chronic Diseases, 3(2), A42.

Corrigan, P. W., \& Phelan, S. M. (2004). Social support and recovery in people with serious mental illnesses. Community Mental Health Journal, 40(6), 513-523.

Corrigan, P. W., Salzer, M., Ralph, R. O., Sangster, Y., \& Keck, L. (2004). Examining the factor structure of the recovery assessment scale. Schizophrenia Bulletin, 30(4), 1035.

Cummins, R. A., \& Lau, A. L. (2003). Community integration or community exposure? 


\section{THE INFLUENCE OF SENSE OF COMMUNITY}

A review and discussion in relation to people with an intellectual disability. Journal of Applied Research in Intellectual Disabilities, 16(2), 145157.

Davis, B. A., Townley, G., \& Kloos, B. (2013). The roles of clinical and nonclinical dimensions of recovery in promoting community activities for individuals with psychiatric disabilities. Psychiatric Rehabilitation Journal, 36(1), 51.

Derogatis, L. R., Lipman, R. S., Rickels, K., Uhlenhuth, E. H., \& Covi, L. (1974). The Hopkins Symptom Checklist (HSCL): A self- report symptom inventory. Behavioral Science, 19(1), 1-15.

Dewees, M., Pulice, R. T., \& McCormick, L. L. (1996). Community integration of former state hospital patients: outcomes of a policy shift in Vermont. Psychiatric Services.

Farkas, M., Gagne, C., Anthony, W., \& Chamberlin, J. (2005). Implementing recovery oriented evidence based programs: Identifying the critical dimensions. Community Mental Health Journal, 41(2), 141-158.

Gulcur, L., Tsemberis, S., Stefancic, A., \& Greenwood, R. M. (2007). Community integration of adults with psychiatric disabilities and histories of homelessness. Community Mental Health Journal, 43(3), 211-228.

Hagell, P., \& Westergren, A. (2011). Measurement properties of the SF-12 health survey in Parkinson's disease. Journal of Parkinson's disease, 1(2), 185-196.

Harding, C. M., Zubin, J., \& Strauss, J. S. (1987). Chronicity in schizophrenia: Fact, partial fact, or artifact?. Psychiatric Services, 38(5), 477-486. 
THE INFLUENCE OF SENSE OF COMMUNITY

Hawkley, L. C., \& Cacioppo, J. T. (2010). Loneliness matters: a theoretical and empirical review of consequences and mechanisms. Annals of Behavioral Medicine, 40(2), 218-227.

Hayes, A. F. (2013). Introduction to Mediation, Moderation, and Conditional Process Analysis: A Regression-based Approach. Guilford Press.

Hayes, A. F., \& Scharkow, M. (2013). The relative trustworthiness of inferential tests of the indirect effect in statistical mediation analysis does method really matter?. Psychological Science, 24(10), 1918-1927.

Hendryx, M., Green, C. A., \& Perrin, N. A. (2009). Social support, activities, and recovery from serious mental illness: STARS study findings. The Journal of Behavioral Health Services \& Research, 36(3), 320-329.

IBM Corporation (2016). IBM SPSS Statistics 24. IBM. Armonk, NY: IBM Corporation.

Jones, D. R., Macias, C., Barreira, P. J., Fisher, W. H., Hargreaves, W. A., \& Harding, C. M. (2004). Prevalence, severity, and co-occurrence of chronic physical health problems of persons with serious mental illness. Psychiatric Services, 55(11), $1250-1257$.

Kaplan, K., Salzer, M. S., \& Brusilovskiy, E. (2012). Community participation as a predictor of recovery-oriented outcomes among emerging and mature adults with mental illnesses. Psychiatric Rehabilitation Journal, 35(3), 219.

Kline, R. (2011). Principles and practice of structural equation modeling ( $3^{\text {rd }}$ edition). New York: Guilford Press.

Kline, R. B. (2015). The mediation myth. Basic and Applied Social Psychology, 37(4), 


\section{THE INFLUENCE OF SENSE OF COMMUNITY}

202-213.

Kloos, B., \& Townley, G. (2011). Investigating the relationship between neighborhood experiences and psychiatric distress for individuals with serious mental illness. Administration and Policy in Mental Health and Mental Health Services Research, 38(2), 105-116.

Kloos, B. (2010). Promoting liberation, well-being, and recovery: Learning from experiences of psychiatric consumers/ survivors. In G. Nelson \& I. Prilleltensky (Eds.), Community Psychology: In Pursuit of Well-being and Liberation, (2nd Ed.) (pp. 453-476). London: Macmillan.Kloos, B., Hill, J., Thomas, E., Wandersman, A., Elias, M., 2012. Community Psychology: Linking Individuals and Communities. Cengage Learning.

Lawrence, D., \& Kisely, S. (2010). Review: Inequalities in healthcare provision for people with severe mental illness. Journal of Psychopharmacology, 24(4 suppl), 61-68.

Link, B. G., Cullen, F. T., Struening, E., Shrout, P. E., \& Dohrenwend, B. P. (1989). A modified labeling theory approach to mental disorders: An empirical assessment. American Sociological Review, 400-423.

Mattsson, M., Topor, A., Cullberg, J., \& Forsell, Y. (2008). Association between financial strain, social network and five-year recovery from first episode psychosis. Social Psychiatry and Psychiatric Epidemiology, 43(12), 947-952.

McMillan, D. W., \& Chavis, D. M. (1986). Sense of community: A definition and theory. Journal of Community Psychology, 14(1), 6-23. 
THE INFLUENCE OF SENSE OF COMMUNITY

Nelson, G., Kloos, B., \& Ornelas, J. (Eds.). (2014). Community psychology and community mental health: Towards transformative change. Oxford University Press.

Nelson, G., Lord, J., \& Ochocka, J. (2001). Empowerment and mental health in community: Narratives of psychiatric consumer/survivors. Journal of Community \& Applied Social Psychology, 11(2), 125-142.

Parks, J., Svendsen, D., Singer, P., Foti, M. E., \& Mauer, B. (2006). Morbidity and mortality in people with serious mental illness. Alexandria, VA: National Association of State Mental Health Program Directors (NASMHPD) Medical Directors Council, 25.

President's New Freedom Commission on Mental Health. Achieving the Promise: Transforming Mental Health Care in America. Rockville, Maryland.

Pinfold, V. (2000). 'Building up safe havens... all around the world': users' experiences of living in the community with mental health problems. Health \& Place, 6(3), 201-212.

Prince, P. N., \& Gerber, G. J. (2005). Subjective well-being and community integration among clients of assertive community treatment. Quality of Life Research, 14(1), 161-169.

Richardson, C. R., Faulkner, G., McDevitt, J., Skrinar, G. S., Hutchinson, D. S., \& Piette, J. D. (2005). Integrating physical activity into mental health services for persons with serious mental illness. Psychiatric Services, 56(3), 324-331.

Robson, D., \& Gray, R. (2007). Serious mental illness and physical health problems: a 


\section{THE INFLUENCE OF SENSE OF COMMUNITY}

discussion paper. International Journal of Nursing Studies, 44(3), 457-466.

Ross, R., \& McGuire, K. A. (2011). Incidental physical activity is positively associated with cardiorespiratory fitness. Medical Science Sports Exercise, 43(11), 2189-94.

Salyers, M. P., Bosworth, H. B., Swanson, J. W., Lamb-Pagone, J., \& Osher, F. C. (2000). Reliability and validity of the SF-12 health survey among people with severe mental illness. Medical Care, 38(11), 1141-1150.

Salzer, M. S., Brusilovskiy, E., Prvu-Bettger, J., \& Kottsieper, P. (2014). Measuring community participation of adults with psychiatric disabilities: Reliability of two modes of data collection. Rehabilitation Psychology, 59(2), 211.

Salzer, M. S., Kottsieper, P., \& Brusilovskiy, E. (2015). Intermethod reliability and factors affecting recall with the Temple University Community Participation measure. Journal of Mental Health, 1-7.

Sandanger, I., Moum, T., Ingebrigtsen, G., Dalgard, O. S., Sørensen, T., \& Bruusgaard, D. (1998). Concordance between symptom screening and diagnostic procedure: The Hopkins Symptom Checklist-25 and the Composite International Diagnostic Interview I. Social Psychiatry and Psychiatric Epidemiology, 33(7), 345-354.

Sarason, S. B. (1974). The Psychological Sense of Community: Prospects for a Community Psychology. San Francisco: Jossey-Bass, 1974.

Seeman, T. E. (1996). Social ties and health: The benefits of social integration. Annals of Epidemiology, 6(5), 442-451.

Segal, S. P., Silverman, C. J., \& Temkin, T. L. (2010). Self-help and community mental 
THE INFLUENCE OF SENSE OF COMMUNITY

health agency outcomes: A recovery-focused randomized controlled

trial. Psychiatric Services, 61(9), 905-910.

Smith, M. K. (2000). Recovery from a severe psychiatric disability: Findings of a qualitative study. Psychiatric Rehabilitation Journal, 24(2), 149.

Talò, C., Mannarini, T., \& Rochira, A. (2014). Sense of community and community participation: A meta-analytic review. Social Indicators Research, 117(1), 1-28.

Tew, J., Ramon, S., Slade, M., Bird, V., Melton, J., \& Le Boutillier, C. (2011). Social factors and recovery from mental health difficulties: a review of the evidence. British Journal of Social Work, 42(3), 443-460.

Townley, G. (2015). “It Helps You Not Feel So Bad-Feel Like You Again”: The Importance of Community for Individuals with Psychiatric Disabilities. Journal of Psychosocial Rehabilitation and Mental Health, 2(2), 113-124.

Townley, G., Brusilovskiy, E., \& Salzer, M. S. (2017). Urban and non-urban differences in community living and participation among individuals with serious mental illnesses. Social Science \& Medicine, 177, 223-230.

Townley, G., \& Kloos, B. (2009). Development of a measure of sense of community for individuals with serious mental illness residing in community settings. Journal of Community Psychology, 37(3), 362.

Townley, G., \& Kloos, B. (2011). Examining the psychological sense of community for individuals with serious mental illness residing in supported housing environments. Community Mental Health Journal, 47(4), 436-446.

Townley, G., Kloos, B., \& Wright, P. A. (2009). Understanding the experience of place: 
THE INFLUENCE OF SENSE OF COMMUNITY

Expanding methods to conceptualize and measure community integration of persons with serious mental illness. Health \& Place, 15(2), 520-531.

Townley, G., Miller, H., \& Kloos, B. (2013). A little goes a long way: The impact of distal social support on community integration and recovery of individuals with psychiatric disabilities. American Journal of Community Psychology, 52(1-2), 8496.

Tsai, J., \& Rosenheck, R. A. (2012). Conceptualizing social integration among formerly homeless adults with severe mental illness. Journal of Community Psychology, 40(4), 456-467.

Tunis, S. L., Croghan, T. W., Heilman, D. K., Johnstone, B. M., \& Obenchain, R. L. (1999). Reliability, validity, and application of the medical outcomes study 36item short-form health survey (SF-36) in schizophrenic patients treated with olanzapine versus haloperidol. Medical Care, 37(7), 678-691.

Üstün, T. B., Chatterji, S., Kostanjsek, N., Rehm, J., Kennedy, C., Epping-Jordan, J., ... \& Pull, C. (2010). Developing the World Health Organization disability assessment schedule 2.0. Bulletin of the World Health Organization, 88(11), 815-823.

Veijola, J., Jokelainen, J., Läksy, K., Kantojärvi, L., Kokkonen, P., Järvelin, M. R., \& Joukamaa, M. (2003). The Hopkins Symptom Checklist-25 in screening DSM-IIIR axis-I disorders. Nordic Journal of Psychiatry, 57(2), 119-123.

Ware Jr, J. E., Kosinski, M., \& Keller, S. D. (1996). A 12-Item Short-Form Health Survey: construction of scales and preliminary tests of reliability and validity. Medical Care, 34(3), 220-233. 
THE INFLUENCE OF SENSE OF COMMUNITY

Ware, N. C., Hopper, K., Tugenberg, T., Dickey, B., \& Fisher, D. (2007). Connectedness and citizenship: Redefining social integration. Psychiatric Services, 58(4), 469474.

Whitley, R., \& Drake, R. E. (2010). Recovery: a dimensional approach. Psychiatric Services.

Wieland, M. E., Rosenstock, J., Kelsey, S. F., Ganguli, M., \& Wisniewski, S. R. (2007). Distal support and community living among individuals diagnosed with schizophrenia and schizoaffective disorder. Psychiatry, 70(1), 1-11.

World Health Organization. (2001). International classification of functioning, disability and health: ICF. World Health Organization.

Wong, Y. L. I., \& Solomon, P. L. (2002). Community integration of persons with psychiatric disabilities in supportive independent housing: A conceptual model and methodological considerations. Mental Health Services Research, 4(1), 13 28.

Yanos, P.T. (2007). Beyond "landscapes of despair": The need for new research on the urban environment, sprawl, and the community integration of persons with serious mental illness. Health and Place, 13, (672-676).

Yanos, P. T., Felton, B. J., Tsemberis, S., \& Frye, V. A. (2007). Exploring the role of housing type, neighborhood characteristics, and lifestyle factors in the community integration of formerly homeless persons diagnosed with mental illness. Journal of Mental Health, 16(6), 703-717.

Yanos, P. T., Stefanic, A., \& Tsemberis, S. (2011). Psychological community integration 


\section{THE INFLUENCE OF SENSE OF COMMUNITY}

among people with psychiatric disabilities and nondisabled community members. Journal of Community Psychology, 39(4), 390-401. 


\section{周 College of Health Professions and Social Work}

TEMPLE UNIVERSITY ${ }^{\circledR}$

\author{
TU Collaborative on \\ Community Inclusion \\ 1700 North Broad Street \\ Suite 313 \\ Philadelphia, PA 19121
}

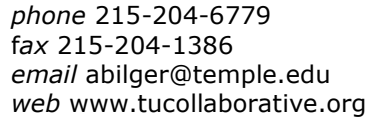

phone 215-204-6779

fax 215-204-1386

email abilger@temple.edu

web www.tucollaborative.org

\section{Participants Wanted for a Paid Research Study}

TITLE:

PURPOSE:
"Understanding factors associated with community living and participation"

We are from Temple University and are conducting a research study over the telephone. This study aims to gather information from individuals with psychiatric disabilities who use publicly-funded services. This study will lead to the development of new policies, programs, and practice interventions.

WHAT'S INVOLVED: If you agree to participate, you will be asked to do a phone survey that will take about 1 hour. You will be asked about activities you participate in, what you think about your neighborhood, and your health symptoms. The study is completely voluntary and private, and your decision to participate will not affect your services.

ELIGIBILITY: 1) adults aged 18-65

2) confirmed diagnosis of schizophrenia, schizoaffective disorder, major depression, or bipolar disorder (manic depression)

3) eligibility for Medicaid or state-equivalent

4) willingness to provide residential address for payment

COMPENSATION: Participants may receive a $\$ 20$ money order in the mail for participating in one phone interview.

CONTACT: If you would like more information about this research study or are interested in participating, please contact Alyssa at 215-204-3007, Jared at 215-204-5593 or Andrea at 215-204-6779. 
Appendix B. Measures.

TEMPLE UNIVERSITY COMMUNITY PARTICIPATION MEASURE

Example:

\begin{tabular}{|c|c|c|c|c|c|c|}
\hline \multirow{2}{*}{$\begin{array}{l}\text { A. How many days during the } \\
\text { past } 30 \text { days did you do the } \\
\text { following activities without a } \\
\text { program staff person going } \\
\text { with you: }\end{array}$} & \multirow{2}{*}{$\begin{array}{c}\text { B. } \\
\text { Numb } \\
\text { er of } \\
\text { Days } \\
\text { (witho } \\
\text { ut a } \\
\text { staff } \\
\text { person } \\
\text { ) } \\
\end{array}$} & \multicolumn{3}{|c|}{ C. Do you do this activity? } & \multicolumn{2}{|c|}{$\begin{array}{c}\text { D. Is this } \\
\text { activity } \\
\text { importa } \\
\text { nt to } \\
\text { you? }\end{array}$} \\
\hline & & $\begin{array}{c}\text { Enoug } \\
\mathbf{h}\end{array}$ & $\begin{array}{c}\text { Not } \\
\text { Enough }\end{array}$ & $\begin{array}{c}\text { Too } \\
\text { Much }\end{array}$ & Yes & No \\
\hline 9. Go to a library. & $\begin{array}{c}\underset{\underline{\mathbf{0}}}{\underline{\mathbf{0}}} \\
\text { (\# of } \\
\text { Days) }\end{array}$ & 1 & 2 & 3 & 1 & 0 \\
\hline $\begin{array}{l}15 . \text { Go to a } 12 \text {-step / self-help } \\
\text { group for substance use } \\
\text { problems. }\end{array}$ & $\begin{array}{c}-\underline{\mathbf{0}}- \\
\underline{\mathbf{5}} \\
\text { (\# of } \\
\text { Days) }\end{array}$ & 1 & 2 & 3 & 1 & 0 \\
\hline
\end{tabular}

\begin{tabular}{|c|c|c|c|c|c|c|}
\hline \multirow{2}{*}{$\begin{array}{l}\text { A. How many days during the } \\
\text { past } 30 \text { days did you do the } \\
\text { following activities without a } \\
\text { program staff person going } \\
\text { with you: }\end{array}$} & \multirow{2}{*}{$\begin{array}{c}\text { B. } \\
\text { Numb } \\
\text { er of } \\
\text { Days } \\
\text { (witho } \\
\text { ut a } \\
\text { staff } \\
\text { perso } \\
\text { n) }\end{array}$} & \multicolumn{3}{|c|}{ C. Do you do this activity? } & \multicolumn{2}{|c|}{$\begin{array}{c}\text { D. Is this } \\
\text { activity } \\
\text { importa } \\
\text { nt to } \\
\text { you? }\end{array}$} \\
\hline & & $\begin{array}{c}\text { Enoug } \\
\text { h }\end{array}$ & $\begin{array}{c}\text { Not } \\
\text { Enough }\end{array}$ & $\begin{array}{c}\text { Too } \\
\text { Much }\end{array}$ & Yes & $\begin{array}{l}\mathbf{N} \\
\mathbf{0}\end{array}$ \\
\hline $\begin{array}{l}\text { 1. Go shopping at a grocery } \\
\text { store, convenience store, } \\
\text { shopping center, mall, other } \\
\text { retail store, flea market, or } \\
\text { garage sale. }\end{array}$ & $\begin{array}{l}\overline{ } \overline{(\# \text { of }} \\
\text { Days) }\end{array}$ & 1 & 2 & 3 & 1 & 0 \\
\hline $\begin{array}{l}\text { 2. Go to a restaurant or coffee } \\
\text { shop. }\end{array}$ & & 1 & 2 & 3 & 1 & 0 \\
\hline
\end{tabular}




\begin{tabular}{|c|c|c|c|c|c|c|}
\hline & $\begin{array}{l}\text { (\# of } \\
\text { Days) }\end{array}$ & & & & & \\
\hline $\begin{array}{l}\text { 3. Go to a church, synagogue, or } \\
\text { place of worship. }\end{array}$ & $\begin{array}{l}\overline{ } \\
\overline{\text { (\# of }} \\
\text { Days) }\end{array}$ & 1 & 2 & 3 & 1 & 0 \\
\hline 4. Go to a movie. & $\begin{array}{c}\overline{ } \\
\overline{\text { (\# of }} \\
\text { Days) }\end{array}$ & 1 & 2 & 3 & 1 & 0 \\
\hline $\begin{array}{l}\text { 5. Go to a park or recreation } \\
\text { center. }\end{array}$ & $\begin{array}{c}\overline{ } \\
\overline{(\# \text { of }} \\
\text { Days })\end{array}$ & 1 & 2 & 3 & 1 & 0 \\
\hline $\begin{array}{l}\text { 6. Go to a theater or cultural } \\
\text { event (including local school or } \\
\text { club events, concerts, exhibits } \\
\text { and presentations in the } \\
\text { community). }\end{array}$ & $\begin{array}{c}\overline{ } \\
\overline{\text { (\# of }} \\
\text { Days) }\end{array}$ & 1 & 2 & 3 & 1 & 0 \\
\hline $\begin{array}{l}\text { 7. Go to a zoo, botanical garden, } \\
\text { or museum. }\end{array}$ & $\begin{array}{c}\overline{ } \\
\overline{(\# \text { of }} \\
\text { Days) }\end{array}$ & 1 & 2 & 3 & 1 & 0 \\
\hline $\begin{array}{l}\text { 8. Go to run errands (for } \\
\text { example, go to a post office, } \\
\text { bank, Laundromat, dry cleaner). }\end{array}$ & $\begin{array}{c}\overline{ } \\
\overline{\text { (\# of }} \\
\text { Days) }\end{array}$ & 1 & 2 & 3 & 1 & 0 \\
\hline 9. Go to a library. & $\begin{array}{l}\overline{-} \\
\text { (\# of } \\
\text { Days) }\end{array}$ & 1 & 2 & 3 & 1 & 0 \\
\hline $\begin{array}{l}\text { 10. Go to watch a sports event } \\
\text { (including bowling, tennis, } \\
\text { basketball, etc.). }\end{array}$ & $\begin{array}{c}\overline{ } \\
\overline{(\# \text { of }} \\
\text { Days) }\end{array}$ & 1 & 2 & 3 & 1 & 0 \\
\hline
\end{tabular}

\begin{tabular}{|c|c|c|c|c|c|c|}
\hline \multirow{2}{*}{$\begin{array}{l}\text { A. How many days during the } \\
\text { past } 30 \text { days did you do the } \\
\text { following activities without a } \\
\text { program staff person going } \\
\text { with you: }\end{array}$} & \multirow{2}{*}{$\begin{array}{l}\text { B. } \\
\text { Num } \\
\text { ber of } \\
\text { Days } \\
\text { (with } \\
\text { out a }\end{array}$} & \multicolumn{3}{|c|}{ C. Do you do this activity? } & \multicolumn{2}{|c|}{$\begin{array}{l}\text { D. Is this } \\
\text { activity } \\
\text { importan } \\
\text { t to you? }\end{array}$} \\
\hline & & $\begin{array}{c}\text { Enoug } \\
\mathbf{h}\end{array}$ & $\begin{array}{c}\text { Not } \\
\text { Enough }\end{array}$ & $\begin{array}{c}\text { Too } \\
\text { Much }\end{array}$ & Yes & No \\
\hline
\end{tabular}




\begin{tabular}{|c|c|c|c|c|c|c|}
\hline & $\begin{array}{c}\text { staff } \\
\text { perso } \\
\text { n) }\end{array}$ & & & & & \\
\hline $\begin{array}{l}\text { 11. Go to a gym, health or } \\
\text { exercise club, including pool, or } \\
\text { participate in a sports event } \\
\text { (including bowling, tennis, } \\
\text { miniature golf, etc.). }\end{array}$ & $\begin{array}{l}\overline{ } \\
\text { (\# of } \\
\text { Days) }\end{array}$ & 1 & 2 & 3 & 1 & 0 \\
\hline $\begin{array}{l}\text { 12. Go to a barber shop, beauty } \\
\text { salon, nail salon, spa. }\end{array}$ & $\begin{array}{l}\overline{-} \\
\overline{\text { (\# of }} \\
\text { Days) }\end{array}$ & 1 & 2 & 3 & 1 & 0 \\
\hline $\begin{array}{l}\text { 13. Use public transportation (for } \\
\text { example, buses, Broad Street } \\
\text { Line, subway) (This does NOT } \\
\text { include mental health agency } \\
\text { vans). }\end{array}$ & $\begin{array}{l}\overline{-} \\
\overline{\text { (\# of }} \\
\text { Days) }\end{array}$ & 1 & 2 & 3 & 1 & 0 \\
\hline $\begin{array}{l}\text { 14. Go to a 12-step / self-help } \\
\text { group for mental health issues. }\end{array}$ & $\begin{array}{l}\overline{ } \\
\overline{\text { (\# of }} \\
\text { Days) }\end{array}$ & 1 & 2 & 3 & 1 & 0 \\
\hline $\begin{array}{l}15 . \text { Go to a } 12 \text {-step / self-help } \\
\text { group for substance use } \\
\text { problems. }\end{array}$ & $\begin{array}{l}\overline{(\# \text { of }} \\
\text { Days) }\end{array}$ & 1 & 2 & 3 & 1 & 0 \\
\hline $\begin{array}{l}\text { 16. Go to another type of support } \\
\text { group in the community (for } \\
\text { example, overeaters anonymous, } \\
\text { gamblers anonymous) (Specify } \\
\text { name of group: }\end{array}$ & $\begin{array}{c}\overline{(\# \text { of }} \\
\text { Days) }\end{array}$ & 1 & 2 & 3 & 1 & 0 \\
\hline $\begin{array}{l}\text { 17. Go to a consumer-run } \\
\text { organization or advocacy } \\
\text { group/organization (This includes } \\
\text { NAMI or any other organization } \\
\text { that is completely run and } \\
\text { operated by mental health } \\
\text { consumers OR an organization or } \\
\text { group that advocates for rights } \\
\text { and services for mental health } \\
\text { consumers). }\end{array}$ & $\begin{array}{l}\text { (\# of } \\
\text { Days) }\end{array}$ & 1 & 2 & 3 & 1 & 0 \\
\hline $\begin{array}{l}\text { 18. Go to a social group in the } \\
\text { community (for example, a book } \\
\text { club, hobby group, other group of } \\
\text { people with similar interests) } \\
\text { (Specify name of }\end{array}$ & $\begin{array}{l}\overline{\text { (\# of }} \\
\text { Days) }\end{array}$ & 1 & 2 & 3 & 1 & 0 \\
\hline
\end{tabular}




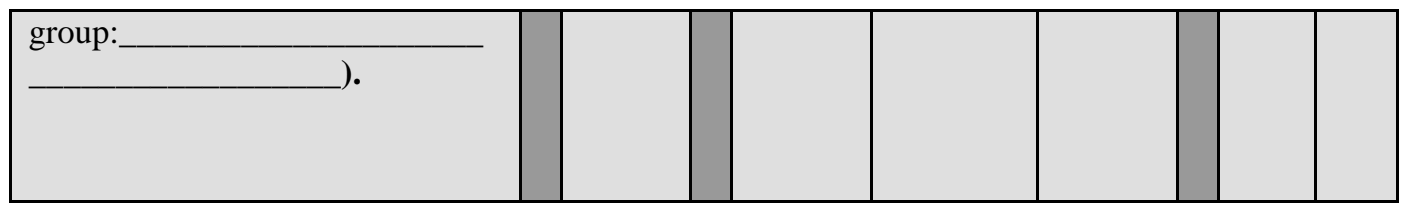

\begin{tabular}{|c|c|c|c|c|c|c|}
\hline \multirow{2}{*}{$\begin{array}{l}\text { A. How many days during the } \\
\text { past } 30 \text { days did you do the } \\
\text { following activities without a } \\
\text { program staff person going } \\
\text { with you: }\end{array}$} & \multirow{2}{*}{$\begin{array}{l}\text { B. } \\
\text { Num } \\
\text { ber of } \\
\text { Days } \\
\text { (with } \\
\text { out a } \\
\text { staff } \\
\text { perso } \\
\text { n) }\end{array}$} & \multicolumn{3}{|c|}{ C. Do you do this activity? } & \multicolumn{2}{|c|}{$\begin{array}{l}\text { D. Is this } \\
\text { activity } \\
\text { importan } \\
\text { t to you? }\end{array}$} \\
\hline & & $\begin{array}{c}\text { Enoug } \\
\mathbf{h}\end{array}$ & $\begin{array}{c}\text { Not } \\
\text { Enough }\end{array}$ & $\begin{array}{c}\text { Too } \\
\text { Much }\end{array}$ & Yes & No \\
\hline 19. Work for pay. & $\begin{array}{l}-\overline{-} \\
\overline{\text { (\# of }} \\
\text { Days) }\end{array}$ & 1 & 2 & 3 & 1 & 0 \\
\hline $\begin{array}{l}\text { 20. Go to school to earn a degree } \\
\text { or certificate (for example: GED, } \\
\text { adult education, college, } \\
\text { vocational or technical school, } \\
\text { job training). }\end{array}$ & $\begin{array}{l}\overline{-} \\
\overline{(\# \text { of }} \\
\text { Days) }\end{array}$ & 1 & 2 & 3 & 1 & 0 \\
\hline $\begin{array}{l}\text { 21. Take a class for leisure or life } \\
\text { skills (for example, classes for } \\
\text { cooking, art crafts, ceramics, and } \\
\text { photography). }\end{array}$ & $\begin{array}{l}\overline{\overline{\text { \# of }}} \\
\text { Days) }\end{array}$ & 1 & 2 & 3 & 1 & 0 \\
\hline $\begin{array}{l}\text { 22. Participate in volunteer } \\
\text { activities (in other words, spend } \\
\text { time helping without being paid). }\end{array}$ & $\begin{array}{l}\overline{(\# \text { of }} \\
\text { Days) }\end{array}$ & 1 & 2 & 3 & 1 & 0 \\
\hline $\begin{array}{l}\text { 23. Get together in the } \\
\text { community or attend an event or } \\
\text { celebration with family or friends } \\
\text { (for example, a wedding, bar } \\
\text { mitzvah). }\end{array}$ & $\begin{array}{l}\overline{-} \\
\overline{\text { (\# of }} \\
\text { Days) }\end{array}$ & 1 & 2 & 3 & 1 & 0 \\
\hline $\begin{array}{l}\text { 24. Entertain family or friends in } \\
\text { your home or visit family or } \\
\text { friends in their homes. }\end{array}$ & $\begin{array}{l}\overline{(\# \text { of }} \\
\text { Days) }\end{array}$ & 1 & 2 & 3 & 1 & 0 \\
\hline
\end{tabular}




\begin{tabular}{|c|c|c|c|c|c|c|}
\hline $\begin{array}{l}\text { 25. Go to a community fair, } \\
\text { block party, community clean-up } \\
\text { day, or other community event or } \\
\text { activity. }\end{array}$ & $\begin{array}{c}\overline{ } \\
\overline{\text { (\# of }} \\
\text { Days) }\end{array}$ & 1 & 2 & 3 & 1 & 0 \\
\hline $\begin{array}{l}26 . \text { Go to or participate in civic } \\
\text { or political activities or } \\
\text { organizations. }\end{array}$ & $\begin{array}{l}\overline{(\# \text { of }} \\
\text { Days })\end{array}$ & 1 & 2 & 3 & 1 & 0 \\
\hline
\end{tabular}




\section{Sense of Community Index- 2}

Please think about your broader community for these questions. We have been talking a lot about your neighborhood, but now I'd like you to think about your community, as in Portland, Gresham, etc.

How important is it to you to feel a sense of community with community members?

\begin{tabular}{|c|c|c|c|c|c|}
\hline $\begin{array}{c}\text { Prefer not } \\
\text { to part of } \\
\text { this } \\
\text { community }\end{array}$ & $\begin{array}{c}\text { Not } \\
\text { important } \\
\text { at all }\end{array}$ & $\begin{array}{c}\text { Not very } \\
\text { important }\end{array}$ & $\begin{array}{c}\text { Somewhat } \\
\text { important }\end{array}$ & Important & $\begin{array}{c}\text { Very } \\
\text { important }\end{array}$ \\
\hline 1 & 2 & 3 & 4 & 5 & 6 \\
\hline
\end{tabular}

How well do each of the following statements represent how you FEEL about this community?

\begin{tabular}{|c|c|c|c|c|}
\hline & \multicolumn{4}{|c|}{$\begin{array}{l}1=\text { not } \text { at all } \\
2=\text { somewhat } \\
3=\text { mostly } \\
4=\text { completely }\end{array}$} \\
\hline $\begin{array}{l}\text { 1. I get important needs of mine met because I am } \\
\text { part of this community }\end{array}$ & 1 & 2 & 3 & 4 \\
\hline $\begin{array}{l}\text { 2. Community members and I value the same } \\
\text { things }\end{array}$ & 1 & 2 & 3 & 4 \\
\hline $\begin{array}{l}\text { 3. Being a member of this community makes me } \\
\text { feel good }\end{array}$ & 1 & 2 & 3 & 4 \\
\hline $\begin{array}{l}\text { 4. When I have a problem, I can talk about it with } \\
\text { members of this community }\end{array}$ & \multicolumn{4}{|c|}{4} \\
\hline 5. I can trust people in this community & 1 & 2 & 3 & 4 \\
\hline $\begin{array}{l}\text { 6. I can recognize most of the members of this } \\
\text { community }\end{array}$ & 1 & 2 & 3 & 4 \\
\hline $\begin{array}{l}\text { 7. I put a lot of time and effort into being part of } \\
\text { this community }\end{array}$ & 1 & 2 & 3 & 4 \\
\hline
\end{tabular}




\begin{tabular}{|c|c|c|c|c|}
\hline $\begin{array}{l}\text { 8. I care about what other community members } \\
\text { think of me }\end{array}$ & 1 & 2 & 3 & 4 \\
\hline 9. I have influence over what this community is like & 1 & 2 & 3 & 4 \\
\hline $\begin{array}{l}\text { 10. If there is a problem in this community, } \\
\text { members can get it solved }\end{array}$ & 1 & 2 & 3 & 4 \\
\hline $\begin{array}{l}\text { 11. I am with other community members a lot and } \\
\text { enjoy being with them }\end{array}$ & 1 & 2 & 3 & 4 \\
\hline $\begin{array}{l}\text { 12. I expect to be part of this community for a long } \\
\text { time }\end{array}$ & 1 & 2 & 3 & 4 \\
\hline $\begin{array}{l}\text { 13. Members of this community have shared } \\
\text { important events together, such as holidays, } \\
\text { celebrations, or disasters }\end{array}$ & 1 & 2 & 3 & 4 \\
\hline
\end{tabular}




\section{$\underline{\mathrm{SF}-12}$}

\section{SF-12v2 ${ }^{\text {тM }}$ Health Survey Standard Version}

This survey asks for your views about your health. This information will help you keep track of how you feel and how well you are able to do your usual activities. Thank you for completing this survey!

For each of the following questions, please click the circle that best describes your answer.

\section{1) In general, would you say your health is:}

\begin{tabular}{ccccc} 
Excellent & Very good & Good & Fair & Poor \\
0 & 0 & 0 & 0 & 0 \\
\hline
\end{tabular}

2) The following questions are about activities you might do during a typical day. Does your health now limit you in these activities? If so, how much?

$\begin{array}{ccc}\text { Yes, } & \text { Yes, } & \text { No, not } \\ \text { limited limited limited } \\ \text { a lot a little at all }\end{array}$

a. Moderate activities, such as moving a table, pushing a vacuum cleaner, bowling, or playing golf

b. Climbing several flights of stairs

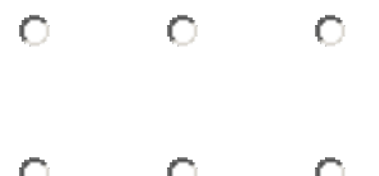

3) During the past 4 weeks, how much of the time have you had any of the following problems with your work or other regular daily activities as a result of your physical health?

All Most
$\begin{gathered}\text { Some } \\ \text { of the of the of the little of the }\end{gathered}$
time time time of the time
time
a. Accomplished less than you would like
b. Were limited in the kind of work or other activities

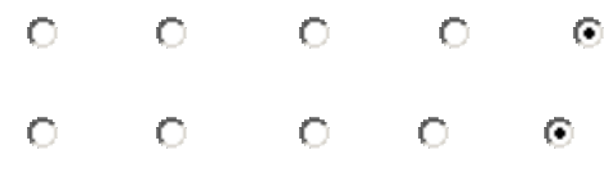


4) During the past 4 weeks, how much of the time have you had any of the following problems with your work or other regular daily activities as a result of any emotional problems (such as feeling depressed or anxious)?

All of Most $\begin{gathered}\text { Some of A little } \\ \text { None } \\ \text { the of the time of the of } \\ \text { time the } \\ \text { time }\end{gathered}$

a. Accomplished less than you would like

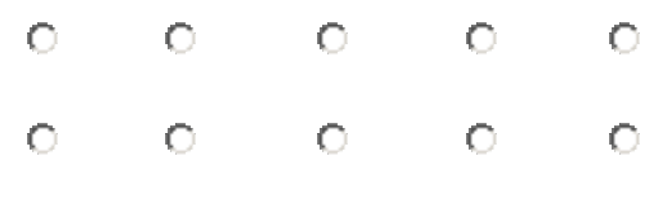

b. Did work or activities less carefully than usual

5) During the past 4 weeks, how much did pain interfere with your normal work (including both work outside the home and housework)?

Not at all

A little bit

Moderately

Quite a bit

Extremely

C

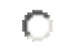

$\mathrm{C}$
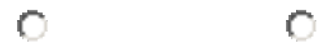

6) These questions are about how you feel and how things have been with youduring the past 4 weeks. For each question, please give the one answer that comes closest to the way you have been feeling. How much of the time during the past 4 weeks...

All of Most of Some of A little None of
the the the time of the
time time
$\begin{gathered}\text { the time } \\ \text { time }\end{gathered}$
a. Have you felt calm and peaceful?

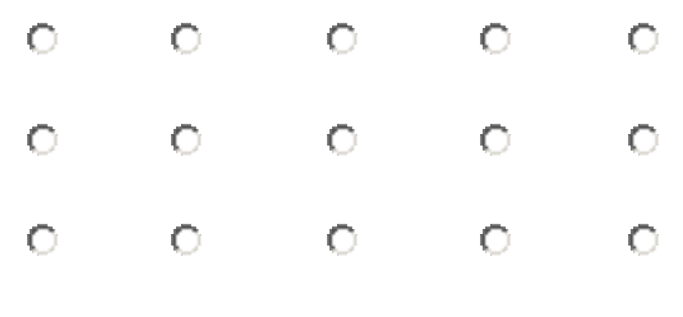

7) During the past 4 weeks, how much of the time has your physical health or emotional problems interfered with your social activities (like visiting friends, relatives, etc.)? 


All of the time $\begin{array}{cccc}\text { Most of the } & \begin{array}{c}\text { Some of the } \\ \text { time }\end{array} & \text { time } & \text { tittle of the } \\ \text { time } & \begin{array}{c}\text { None of the } \\ \text { time }\end{array}\end{array}$




\section{Hopkins Symptom Checklist}

Please turn to card \#24. I will now read a list of problems and complaints that people sometimes have. Please tell me how much each problem has bothered or distressed you during the past week, including today.

\begin{tabular}{|c|c|c|c|c|}
\hline $\begin{array}{l}\text { How bothered or distressed have you } \\
\text { been during the past week by } \ldots \text {. . }\end{array}$ & $\begin{array}{l}\text { Not at } \\
\text { All }\end{array}$ & $\begin{array}{l}\text { A } \\
\text { Little }\end{array}$ & $\begin{array}{l}\text { Quite } \\
\text { a Bit }\end{array}$ & Extremely \\
\hline 1.Being scared for no reason? & 1 & 2 & 3 & 4 \\
\hline 2. Feeling fearful? & 1 & 2 & 3 & 4 \\
\hline 3. Faintness? & 1 & 2 & 3 & 4 \\
\hline 4. Nervousness? & 1 & 2 & 3 & 4 \\
\hline 5. Heart racing? & 1 & 2 & 3 & 4 \\
\hline 6. Trembling? & 1 & 2 & 3 & 4 \\
\hline 7. Feeling tense? & 1 & 2 & 3 & 4 \\
\hline 8. Headache? & 1 & 2 & 3 & 4 \\
\hline 9. Feeling panic? & 1 & 2 & 3 & 4 \\
\hline 10. Feeling restless? & 1 & 2 & 3 & 4 \\
\hline 11. Feeling low in energy? & 1 & 2 & 3 & 4 \\
\hline 12. Blaming oneself? & 1 & 2 & 3 & 4 \\
\hline 13. Crying easily? & 1 & 2 & 3 & 4 \\
\hline 14. Losing sexual interest? & 1 & 2 & 3 & 4 \\
\hline 15. Feeling lonely? & 1 & 2 & 3 & 4 \\
\hline
\end{tabular}




\begin{tabular}{|l|c|c|c|c|}
\hline 16. Feeling hopeless? & 1 & 2 & 3 & 4 \\
\hline 17. Feeling blue? & 1 & 2 & 3 & 4 \\
\hline 18. Thinking of ending one's life? & 1 & 2 & 3 & 4 \\
\hline 19. Feeling trapped? & 1 & 2 & 3 & 4 \\
\hline 20. Worrying too much? & 1 & 2 & 3 & 4 \\
\hline 21. Feeling no interest in things? & 1 & 2 & 3 & 4 \\
\hline $\begin{array}{l}\text { 22. Feeling that everything is an } \\
\text { effort? }\end{array}$ & 1 & 2 & 3 & 4 \\
\hline 23. Worthless feeling? & 1 & 2 & 3 & 4 \\
\hline 24. Poor appetite? & 1 & 2 & 3 & 4 \\
\hline 25. Sleep disturbance? & & 2 & 3 & 4 \\
\hline
\end{tabular}

